\title{
Dumping and Double Crossing: The (In)Effectiveness Of Cost-Based Trade Policy Under Incomplete Information
}

\author{
Dobrin R. Kolev* Thomas J. Prusa ${ }^{\dagger, \ddagger}$
}

January 8, 1999

\begin{abstract}
We argue that the rise of antidumping protection and the proliferation of voluntary export restraints are fundamentally inter-related. We show that both can be explained by a cost-based definition of dumping when the domestic government has incomplete information about the foreign firm's costs. Given that its costs are only imperfectly observed and knowing the government's desire to offer greater protection against competitively priced imports, efficient foreign firms will voluntarily restrains their exports prior to the antidumping investigation. In turn, the VER distorts the government's perception of the foreign firm's efficiency and often leads to undesirably high duties regardless of the foreign firm's efficiency. The clumsy way that duties are levied benefits domestic firms, which explains the popularity of cost-based complaints.
\end{abstract}

Key words: Antidumping law; Voluntary export restraints; Incomplete information JEL classification: F13; D82; L13

*Mitchell Madison Group, 520 Madison Avenue, New York, New York 10022, USA. e-mail: kolev@mmgnet.com

${ }^{\dagger}$ Department of Economics, Rutgers University, New Brunswick, NJ 08901-1248, USA and NBER. phone: (732) 932-7670, fax: (732) 932-7416, e-mail: prusa@econ.rutgers.edu

${ }^{\ddagger}$ We would like to thank the seminar participants at Princeton University, Columbia University, and Syracuse University and also Kyle Bagwell, Pradeep Dubey, John Hillas, Rich McLean, and Daijiro Okada for their many helpful comments and discussions. 


\section{Introduction}

In this paper we show that the two most widely given explanations for the rise of protection over the past twenty years - antidumping protection and voluntary export restraints - are fundamentally inter-related. ${ }^{1}$ We argue that voluntary export restraints (VERs) are a natural consequence of cost-based antidumping (AD) legislation. Specifically, when governments implement cost-based AD under incomplete information about foreign costs, foreign firms undertake VERs in an attempt to convince domestic authorities that they are not competitive threats. We show that under typical circumstances VERs simply muddle the government's perception and lead it to levy AD duties in a very clumsy and inefficient fashion. In fact, we show that although cost-based AD raises welfare under complete information, the distortions inherent with implementing it under incomplete information make it an undesirable policy.

Three important institutional characteristics of AD law motivate our approach. First, cost-based AD petitions have become "the dominant feature of U.S. antidumping law" (Horlick, 1989, p. 136). Traditionally, dumping was defined as international price discrimination, but in 1974 the definition was broadened to include sales below cost. ${ }^{2}$ According to Clarida (1996) since 1980 between one-half and two-thirds of U.S. AD cases have been conducted using the cost-based definition of dumping. ${ }^{3}$ Not coincidentally, Bhagwati (1988) and Krueger (1995) both date the rapid increase in high-track (VERs) and low-track (AD duties) restraints to the mid-1970s. From this perspective, if one seeks to understand the rise of $\mathrm{AD}$ protection and the proliferation of VERs, cost-based AD policy is a sensible place to start.

Second, governments implement cost-based dumping under incomplete information. Under cost-based dumping, the domestic government estimates the foreign firm's production costs and then constructs an $\mathrm{AD}$ duty designed to insure that the exporter's price is "fair." Not surprisingly, the ambiguous nature of estimating the foreign firm's

\footnotetext{
${ }^{1}$ Almost $10 \%$ of U.S. imports were covered by antidumping orders in 1990, almost triple the coverage in 1980. During the same period the number of VERs doubled (Krueger, 1995; Low, 1993).

${ }^{2}$ Clarida (1993) and Ethier (1982) explain why firms sell below cost but neither incorporates VERs into their analysis.

${ }^{3}$ Different methods and definitions for evaluating Department of Commerce methodology explains the different estimates. Note also that the EC, the other major user of AD, has similarly embraced costbased methodology. Messerlin (1989) estimates that over $90 \%$ of EC cases against developing countries are based on constructed costs.
} 
costs is the source of numerous complaints. Foreign defendants often claim that estimated costs have nothing to do with their actual costs. Rules such as the use of "best information available," which bases the cost estimate on the domestic firm's estimate of foreign costs, and ad hoc methods such as basing cost estimates on third market surrogates make AD procedures quite capricious. Cost uncertainty in conjunction with the arbitrariness of the methods for constructing costs makes AD an ominous threat for all foreign firms regardless of their true efficiency.

Third, foreign firms often undertake VERs prior to any AD investigation hoping to appease domestic cries for protection. For instance, the 1981 automobile VER, perhaps the best known VER, was negotiated under the threat of an AD action. Similarly, many of the steel restraints undertaken in the mid-1980s were negotiated under the threat of imminent AD action. Krueger (1995, p. 35) states that "threats of administered protection have induced trading partners to accept other bilateral measures, such as VERs" (emphasis added). A senior negotiator in the semiconductor dispute stated that the U.S. industry used "the threat of the dumping case to stimulate broad negotiations on all aspects of the problem" (Prestowitz, 1988, p. 196, emphasis added). In such circumstances, the VER is conceived of as a "pressure-release valve," where foreign firms reduce exports until protectionist sentiments subside.

We incorporate these three institutional features into a stylized model and demonstrate how VERs and cost-based AD are inter-related. The starting point for our analysis is the long understood insight that governments have an incentive to implement cost-contingent protection (Brander and Spencer, 1984). We interpret cost-based AD as a GATT/WTO sanctioned vehicle for implementing a cost-contingent tariff policy. While this interpretation of cost-based procedures differs from GATT guidelines, many Department of Commerce (DOC) decisions are so perplexing that the our interpretation is a plausible view how AD is implemented in practice (Boltuck and Litan, 1991).

We also suppose that the home government cannot observe the foreign firm's costs; we show that this induces the foreign firm to announce a VER in order to signal its (in)efficiency in an attempt to reduce the size of the potential duty. In other words, the foreign firm agrees to restrain sales in order to forestall calls for even more restrictive measures.

Interestingly, as is often the case in practice we find that the VER fails to release the protectionist pressures and domestic industries clamor for more protection. For 
instance, despite the measures taken by the Japanese semiconductor producers to diffuse the calls for protection, a cost-based AD complaint was ultimately filed. In fact, a review of $\mathrm{AD}$ cases suggests that preemptive export restraints have only had mixed success at averting AD investigations. As a noted AD expert stated, VERs "have certainly been instrumental in preventing a number of antidumping proceedings from arising, but (they are not) ... a substitute for relief" (Bellis, 1989, p. 54). Moreover, and perhaps most surprising, we find that the VER causes the AD duties to be particularly ineptly levied: excessively high duties are assessed against inefficient exporters and undesirably low duties are imposed on efficient producers. In other words, the preemptive VER not only does a poor job releasing protectionist pressures, but is at least partly responsible for the widespread perception the AD duties are often excessive.

Our approach differs from Harris (1985) and Krishna (1989) who emphasize the collusive and cartel-enhancing features of VERs. ${ }^{4}$ While the facilitating practice explanation is a powerful ex post justification for VERs, we have found no evidence that collusion was the original motivation for a VER at the outset of any trade dispute. As Low (1993, p. 114) succinctly stated, saying that a VER is voluntary "is like saying that a man asked to be shot in the foot, without mentioning that he had the choice of being shot in the foot or in the head."

Our paper complements the recent work by Anderson (1992) and Rosendorff (1996). Both study the interaction between VERs and AD duties, but their models differ from ours in several important ways. In both their models the VER is undertaken after the $\mathrm{AD}$ complaint is already filed; we suppose the VER is undertaken before the AD petition is filed. More significantly, they assume that the VER is a substitute for AD protection (i.e., the VER is assumed to release pressure). In our model the extent to which the VER forestalls further AD activity is endogenously determined.

Our analysis is also of interest from a technical viewpoint. We show that the standard "single crossing" property (also referred to as the Spence-Mirrlees sorting condition) does not hold in our model. In our context a key issue is the extent to which producers are willing to restrain exports in order to avoid the AD duty. For a given duty, if at every quantity level inefficient producers were more willing to restrain output than more efficient producers, then the single crossing condition would be satisfied. We demonstrate that single crossing does not hold and that producers' preferences are

\footnotetext{
${ }^{4}$ Staiger and Wolak $(1989,1992)$ and Prusa (1992) also emphasize AD's role for maintaining cartels.
} 
characterized by a "double crossing" property.

If the model were characterized by single crossing, it is well known from the work of Cho and Sobel (1990) that the stable equilibrium involves separation, albeit with some distortion to trade. If this were the case then cost-based $\mathrm{AD}$ could be justified, at least to the extent that duties were being levied optimally. We show that double crossing inhibits firms' ability to separate and leads to pooling. This in turn implies AD duties are levied sub-optimally. Thus, distortions occur before and after the investigation, making cost-based AD a particularly futile policy.

Bernheim $(1991,1994)$ has examined dividend policy and social behavior when indifference curves violate single crossing. Bagwell and Bernheim (1996) also argue that Veblen effects in consumption arise when single crossing fails. The similarities between our model and these papers is largely limited to the equilibrium refinement used and the persistence of pooling outcomes. However, the nature of the underlying preferences, the structure of the games, and the characterization of the resulting equilibrium are substantially different. The properties of our model are closest to those of Cho (1994) who revisits the limit pricing argument of Milgrom and Roberts (1982).

The paper proceeds as follows. In the next section we provide some additional background on AD law to motivate our modeling approach. In Section 3 we describe the extensive form of the game and in Section 4 solve for the unique equilibrium behavior of the players once the dumping case is completed. However, as is the case in most signaling games, there is a plethora of equilibria in the overall game. In Section 5 we discuss reasonable beliefs refinements and establish the equilibrium concept. Readers interested primarily in the intuition of the results may prefer to skip the technical discussion contained in this section. In Section 6 we provide the solution to the model and in Section 7 we show that a pooling outcome emerges under most reasonable demand and cost parameter values. The welfare implications of cost-based AD are discussed in Section 8. Policy implications and the applicability of our findings to other economic issues are discussed in Section 9.

\section{Antidumping as a threat}

Under GATT/WTO rules, AD duties can be levied if (i) imports are sold at less than fair value and (ii) these imports cause material injury to the domestic industry. Under 
current rules both parts of the AD determination are quite easy to satisfy. Since 1980 the DOC has found dumping in $95 \%$ of its decisions (Hansen and Prusa, 1995). As Low (1993, p. 86) states "virtually any industry that considers itself adversely affected by foreign competition and presents a competently assembled petition, stands a good chance demonstrating ... that it is under attack."

There is little doubt that the law is heavily biased against foreign firms (Boltuck and Litan, 1991). It often appears that the government does not attempt to accurately measure costs. Consider for instance that any failure by the foreign firm to respond to the DOC's onerous reporting requirements allows the DOC to disregard all its data and instead use the best information available, which typically means data reported in the domestic firm's petition (Murray, 1991). Further, after the foreign firm's variable costs are estimated DOC adds $10 \%$ for overhead and $8 \%$ for profit, additions undoubtedly distort costs. ${ }^{5}$

The arbitrariness of $\mathrm{AD}$ proceedings surely encourages foreign firms to take actions to avoid them. In addition, the legal costs surrounding an $\mathrm{AD}$ investigation are often prohibitive with estimates typically in the range of $\$ 500,000$ to $\$ 1$ million per firm (Braga and Silber, 1993; Mendez, 1993). Moreover, if the foreign firm is unlucky enough to be named in an $\mathrm{AD}$ case and have its case completed, it is usually confronted with a formidable tariff barrier. For example, during 1990 and 1991, the average AD duty was $55.5 \%$, as compared with those products average MFN tariff of $14.4 \%$ (Anderson, 1993). ${ }^{6}$

With its ominous record of restricting trade, deterrence appears to be at the heart of the U.S.'s antidumping policy. For example Krueger (1995, p. 35) states that AD law is designed "with the clear intent of pressuring for a VER." As mentioned above, semiconductors and automobiles are both examples of how the threat of an AD petition can spur a VER.

The three key elements of our model, however, are most clearly evidenced by the steel industry, by far the heaviest user of the law, accounting for more than one-third of all AD petitions. First, most steel petitions are based on cost allegations (Clarida, 1996). Interestingly, it was at the behest of the steel industry that the definition of

\footnotetext{
${ }^{5}$ For perspective, in 1989 only two of the fifteen largest companies in the Fortune 500 passed the $8 \%$ profit test.

${ }^{6}$ The trade consequences of such large duties are dramatic: Hoekman and Leidy (1991) find that on average targeted imports are 40 percent lower three years after AD duties are levied.
} 
dumping was broadened to include sales below cost in 1974 .

Second, the steel industry uses the specter of AD investigations to deter foreign producers. The industry is a master at raising the visibility of their plight and threatening burdensome trade restraints. These threats have not been wasted as producers from all over the world have restrained steel exports in order to avoid the credible threat of an $\mathrm{AD}$ investigation.

Third, steel petitions are most often threatened against the most efficient producers. For example, in 1978 estimated costs for a ton of steel were $\$ 71$ in Japan and $\$ 114$ in the U.S. (Jones, 1986). The fact that the Japanese were so much more efficient than other foreign producers was precisely the reason why they were targeted by the U.S. In calculating its preliminary margin, the DOC based its estimates on data provided by the plaintiff in accordance with the "best information available" principle and established a duty of 32 percent. Patrick and Sato (1982) report that when the "Japanese industry came to realize it would benefit more from high rather than low cost estimates" the executives of the major steel firms initiated talks for a VER. ${ }^{7}$ But, while the efficient Japanese have been targeted in a number of AD petitions, hundreds of $\mathrm{AD}$ petitions have also been filed against less efficient steel producers. Naturally, the burden of AD duties have been heavier for relatively inefficient producers.

\section{The Model}

We describe a scenario where a single foreign producer competes against a home firm under the scrutiny of the home government. Broadly speaking, the game can be thought of as occurring in two distinct phases: pre-AD and post-AD determination. During the first part of the game the foreign firm is aware of the build-up of protectionist pressure. It also understands the home country's rent-extracting and profit-shifting incentives for implementing an $\mathrm{AD}$ policy where lower cost firms will be subject to higher AD duties. Thus, during the first part of the game the foreign firm's export decision is strategic since it can influence the government's posterior beliefs about the foreign firm's efficiency. We will show that the export decision involves a choice of either myopic profit maximization

\footnotetext{
${ }^{7}$ The 1977 steel dispute was resolved with the trigger price mechanism (which explicitly based market prices on the DOC's estimates of Japanese costs). This agreement fell apart partly because of Japan's unhappiness with bearing a disproportionate share of the total decrease in steel exports. Within a few years the trigger price was replaced with explicit quantity restrictions.
} 
or a VER which might conceal the firm's true type and alleviate protectionist sentiments.

The extensive form of the game has the following structure. The foreign firm's constant marginal cost is drawn from the set $\mathcal{T}=\left\{C_{1}, \ldots, C_{T}\right\}$, with $C_{i}<C_{j}$ for $i<j$, according to a commonly known probability distribution, $\mu$. The realization of the cost is private information for the exporter and will be referred to as its type. For simplicity we will use $i$ to denote the type of exporter with true cost $C_{i}$.

In the first period, we assume that the foreign firm's exports are subject to a specific tariff of $\tau_{0} \geq 0$. Given this information, the foreign firm chooses and announces its first period export quantity, $Q$. Following the decision of its rival, the home firm chooses its first period quantity, $q$.

At the conclusion of the first stage the government observes the level of imports and home production and then forms beliefs about the efficiency of the foreign firm. If an $\mathrm{AD}$ petition is filed, the government selects a per unit $\mathrm{AD}$ duty, $\tau_{D} \geq 0$, which will remain in effect during the next $N$ periods of trade. Given the level of the AD duty the two firms compete simultaneously in quantities for the remainder of the game.

A couple of comments about the design of the game are in order. First, we are modeling a situation where the home government has an AD statute and the home firm has an opportunity to file an $\mathrm{AD}$ petition at the end of the first period. As discussed above, it is not the foreign firm's costs per se that are the impetus for the investigation, but rather the high level of trade associated with an efficient firm. Thus, the foreign firm has an incentive to voluntarily restrict its exports in order to reduce the potential duty. Moreover, it is common knowledge that the foreign firm is likely to announce a VER; therefore it is natural to assume that the home firm will wait to observe the foreign firm's actions before proceeding with first period sales and its filing decision. Thus, we model the home firm as a Stackelberg follower. ${ }^{8}$ Besides this intuitive justification for the Stackelberg assumption, in a game with simultaneous moves, verifying the incentives of the foreign firm to deviate from a given equilibrium while holding the action of the domestic producer fixed does not seem sensible if the deviation cannot be supported by another reasonable equilibrium.

Second, as is common in the signaling literature, we assume that the home firm

\footnotetext{
${ }^{8}$ Since there is no obvious reason to give any firm the advantage of a first mover in subsequent periods we model the competition à la Cournot. Furthermore, the mode of competition is inessential for the analysis of the post-duty subgame.
} 
learns the true costs of the foreign firm after the $\mathrm{AD}$ investigation. ${ }^{9}$

Finally, demand in the home country is assumed to be linear $p=a-Q-q$. This simple functional form will allow us to describe the behavior of the players without resorting to abstract arguments.

\section{Analysis of the subgame following the AD petition}

\subsection{Firm decisions}

We are looking for a solution which will prescribe a self-enforcing norm of behavior for each of the three players. This implies that at minimum the selected equilibria should satisfy backward induction. Since the subgame starting after the government chooses an AD duty has a finite number of periods, $N$, the linear structure of the model guarantees that it has a unique path which is part of a subgame perfect equilibrium.

In any stage $n$ of this proper subgame a type $i$ foreign firm takes the total per unit levy, $t=\tau_{0}+\tau_{D}$, as given and maximizes its (variable) profit function

$$
\pi_{i}(Q, q, t)=Q(a-Q-q)-t Q-C_{i} Q
$$

The per-period payoff for the domestic firm is

$$
\phi(Q, q)=q(a-Q-q)-c_{d} q
$$

where $c_{d}$ denotes the domestic firm's marginal costs.

At each stage the resulting optimum quantity for a type $i$ exporter is

$$
\widetilde{Q}_{i}^{n}=\left(a+c_{d}-2 C_{i}-2 t\right) / 3
$$

and for the domestic firm is

$$
\tilde{q}^{n}(i)=\left(a+C_{i}+t-2 c_{d}\right) / 3,
$$

\footnotetext{
${ }^{9}$ If costs are not revealed after the determination is made, we would enter a typical limit pricing game in which the efficient types would try to prove themselves. This would shift the analysis away from the issue at hand. Of course, such problems would not arise if competition continues to be sequential in future periods.
} 
where we use the superscript $n$ to denote that these are solutions to the subgame following the $\mathrm{AD}$ duty.

The total profit (over all $N$ periods following the AD duty) is

$$
N \cdot \widetilde{\pi}_{i}^{n}=(N / 9)\left(a+c_{d}-2 C_{i}-2 t\right)^{2} \quad \text { and } \quad N \cdot \widetilde{\phi}^{n}(i)=(N / 9)\left(a+C_{i}+t-2 c_{d}\right)^{2} .
$$

\subsection{Optimal AD duty}

As discussed earlier, we will assume that the government uses its cost-based policy to implement a duty that maximizes host country welfare. While this assumption does not follow official AD procedures it does seem consistent with empirical evidence and captures the more general pressures on governments to devise efficient protection schemes.

Assuming for the moment that the host government could observe the true cost of the exporter its payoff for the $N$ period subgame would be the sum of consumer surplus, profit of the domestic producer and tariff revenue

$$
w=N\left[(Q+q)^{2} / 2+\phi(Q, q)+t Q\right] .
$$

Using the unique subgame outcomes the welfare can be expressed as

$$
\begin{aligned}
w(i, t)=N[ & \left(2 a-C_{i}-c_{d}-t\right)^{2} / 18+\left(a+C_{i}+t-2 c_{d}\right)^{2} / 9+ \\
& \left.+t\left(a+c_{d}-2 C_{i}-2 t\right) / 3\right] .
\end{aligned}
$$

When an $\mathrm{AD}$ petition is filed the government chooses $\tau_{D}$ to maximize (5), yielding a total levy of

$$
\tilde{t}_{i}=\left(a-C_{i}\right) / 3
$$

The above expression makes it clear that higher duties are levied against more efficient exporters. If an efficient exporter does not voluntarily restrict first period exports and behave like a more inefficient exporter and if a petition is filed, the home government would levy an $\mathrm{AD}$ duty in the amount of $\tau_{D}=\tilde{t}_{i}-\tau_{0}$. From this point on, a total tariff $t>\tau_{0}$ is to be understood as the initial tariff plus an $\mathrm{AD}$ surcharge equal to $t-\tau_{0}$.

Hence we will use the terms tariff and duty interchangeably to describe the total level 
of protection. To keep the model as simple as possible, we will assume that $\tau_{0} \leq \tilde{t}_{T}$, which implies that an $\mathrm{AD}$ petition will be filed against all types. ${ }^{10}$

Finally, we note that the marginal benefit to the home country from lowering the AD duty is increasing in $C_{i}$. This implies that the government's best response is monotonically decreasing in the posterior likelihood of a more inefficient exporter. This explains the desire of each type to be considered type $T$.

\section{The Equilibrium Concept}

Solving the game backwards we proceed to analyze the first stage. In this three-player signaling game the foreign firm (the sender) signals its type through its export choice; the home firm then chooses its output level and whether to file a petition; finally, the government (the receiver) levies an $\mathrm{AD}$ duty based on its beliefs about the type of the exporter. The payoffs from a selected strategy profile in this reduced game are given by adding the first period profit and welfare to the Cournot subgame profit and welfare defined above.

Since any reasonable equilibrium must involve the unique outcome in the second stage Cournot subgame, any concerns about the multiplicity and reasonableness of equilibria will stem from first period actions. We will refer to a solution to this reduced game as a self-enforcing outcome for the whole game. ${ }^{11}$

In games with incomplete information the formation of beliefs is often controversial. We would like to find a solution which is supported by a reasonable belief-formation process. From a game theoretic standpoint we want our equilibria to resemble closely the properties of a strategically stable set as defined by Kohlberg and Mertens (1986). ${ }^{12}$

\footnotetext{
${ }^{10}$ This is not a restrictive assumption since the most frequent users of cost-based AD, the U.S. and the EC, also have very low MFN tariffs. In addition, a higher initial tariff would introduce another stage to the game without providing additional insight. At this stage, the domestic firm would make a decision whether to file a petition. Since the beliefs of the government are common knowledge in equilibrium, the firm would obviously file a petition if the beliefs entail a positive AD duty.

${ }^{11}$ In general, a self-enforcing outcome of a game need not induce a stable outcome in every subgame or vice versa. However, under conditions satisfied by our model Cho (1993) shows that in two-player senderreceiver games (with finite strategy spaces) a strategically stable outcome (in the sense of Kohlberg and Mertens, 1986) contains an equilibrium which induces a stable outcome in every subgame.

${ }^{12}$ Strict reference to stability throughout the paper is not warranted, however, since the concept is not defined for games with continuum of strategies. Our game can be viewed as an approximation to a game with a large finite number of strategies. For an extensive discussion of stability in the context of signaling games we recommend the excellent book by van Damme (1987).
} 
Cho and Kreps (1987) and Banks and Sobel (1987) provide reasonable restrictions on the beliefs of the receiver off the equilibrium path which do not eliminate and often lead to the unique stable component in two-player signaling games. We will now extend their arguments to our three-player model and describe the equilibrium concept which we will employ.

The first requirement we impose on our equilibria is that they are sequential (Kreps and Wilson, 1982). ${ }^{13}$ Hence we require (a) all players to maximize their respective payoff functions given the strategies of the others and the beliefs of the government (sequential rationality) and (b) the induced beliefs about the firm's cost at each export level obtained with positive probability should be compatible with the strategies of the two firms in the sense of Bayes' rule (consistency). At quantities exported with probability zero any beliefs which rationalize the behavior of the government are permissible.

The requirement that the solutions be sequential equilibria is quite weak. In fact, the only new element which the above restriction introduces in addition to the requirements for a Nash equilibrium is that at zero probability export levels the government is not allowed to announce irrational duties. The sequential equilibrium concept allows for a multiplicity of beliefs off the equilibrium path. Hence, if we impose only this restriction our game will have a continuum of pooling, semi-pooling, and separating equilibria.

Following the general program developed by Cho and Kreps (1987) and Banks and Sobel (1987) we will refine the set of sequential equilibria by eliminating those which assign unreasonable beliefs at null events. In particular, we will require the government to perceive each out of equilibrium quantity as a possible signal by the exporter and place probability zero on a type which is unlikely to send it.

Suppose that we have a sequential equilibrium whose stability we would like to check. Let one of the three players contemplate deviating from the proposed equilibrium. The first restriction that we impose requires this player (a) take into account all combinations of best responses by the other players at information sets likely to be reached by the deviation strategy ${ }^{14}$ and (b) disregard all pure actions which do not maximize his payoff at a given information set, holding the strategies of the other players fixed. In our

\footnotetext{
${ }^{13}$ Since the sequential equilibria concept is not defined for games with a continuum of strategies, we work with its extension provided by Kreps and Sobel (1994).

${ }^{14}$ In his formulation of a forward induction equilibrium Cho (1987) imposes the same requirement for general extensive games. His subsequent restrictions, however, are weaker than the ones we employ in this paper.
} 
context this means that the AD duties available to the government are those which can be rationalized by some beliefs about the type of exporter. The restriction also implies that the only strategy that the home firm has is its unique (Stackelberg follower) maximizer.

Despite its intuitive appeal such a reduction of the game is ad hoc and may lead to the elimination of reasonable equilibria. The above process can be justified in finite games by a well known result due to Kohlberg and Mertens (1986). They show that for any game and a stable set of equilibria of that game if a pure strategy of a player does worse in every equilibrium than his equilibrium prescription (i.e., if the strategy is never a weak best response relative to the set), then after deleting this strategy from the action set of that player, the subset of equilibria of the original stable set which assign probability zero to that particular action contains a set which is stable in the restricted game. The same result holds if a pure strategy is dominated.

We now assert that a strategy which is not a best reply for the government and the home firm to a given level of exports is strictly dominated. ${ }^{15}$ Hence, the result of Kohlberg and Mertens (1986) guarantees that we will not discard a stable outcome if as a first step in the refinement process we restrict the strategy sets of the government and the home firm to their respective best responses.

In proving our claim, it is important to realize that the best reply function of the government is independent of the first period strategy of the home firm. Figure 1 can be useful in clarifying this point. In order to make our argument as clear as possible, we depict a simplified version where there are only two types $(T=2)$ and each player only has two pure actions. As depicted, nature chooses the foreign firm's type (1 or 2$)$; after observing its type, the foreign firm makes an export choice $\left(Q_{1}\right.$ or $\left.Q_{2}\right)$; the home firm then chooses its production level ( $q_{1}$ or $\left.q_{2}\right)$; finally, the government levies a duty $\left(t_{1}\right.$ or $\left.t_{2}\right)$.

Consider a pair of strategies for the foreign and home firms such that the information set of the government after $\left(Q_{1}, q_{1}\right)$ is reached with positive probability (i.e., the set containing the nodes $x$ and $y$ ). The best response of the government at that information set depends on the relative likelihood of the two nodes. Each node, however, is reached by the home firm playing $q_{1}$ with the same probability. Hence, the only relevant information for the optimization problem at the government's information set comes from

\footnotetext{
${ }^{15}$ This claim is true for all two-player games but need not hold in games with more players.
} 


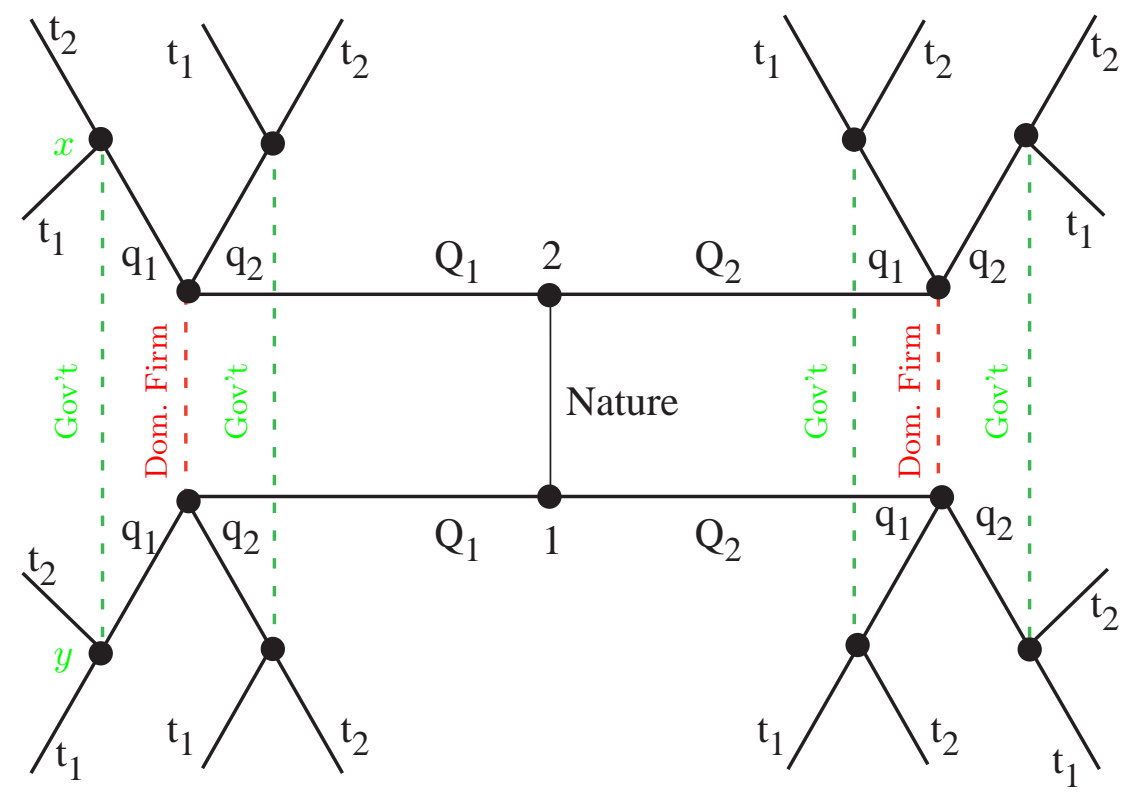

Figure 1: The extensive form of the first period subgame (2 types, 2 actions)

the randomizations of nature and the exporter. Therefore, the proof of our claim that a strategy that is not a best reply for the government is strictly dominated is the same as in two-player games and is a standard application of the separating hyperplane theorem (Fudenberg and Tirole, 1992).

Applying similar arguments it is also clear that the home firm's best response function does not depend on the strategy of the government. Given any choice of exports and AD duty, the home firm will produce its unique Stackelberg maximizer. Every other action of the home firm can be discarded on the basis of the proposition of Kohlberg and Mertens (1986).

The restrictions on the behavior of the foreign firm which we require constitute a straightforward adaptation of the $D_{1}$ criterion of Cho and Kreps (1987) which is based on the notion of universal divinity of Banks and Sobel (1987). This refinement is now formally presented.

Fix a probability distribution over the end points of the signaling subgame induced by a sequential equilibrium in which an exporter of type $i$ obtains a profit (over all 
periods) of $\Pi_{i}^{*}$. Call this probability the outcome of the game associated with the given equilibrium. Fix also an out of equilibrium export level, $Q^{\prime}$. Let $B R\left(\eta, Q^{\prime}\right)$ denote the set of best responses of the government at $Q^{\prime}$ given that (a) the induced beliefs about the types exporting this quantity are $\eta$ and (b) the home firm produces its unique maximizer when it observes $Q^{\prime}$. Write element $i$ of $\eta$ as $\eta\left(i \mid Q^{\prime}\right)$. Then

$$
B R\left(\eta, Q^{\prime}\right) \equiv \underset{t \in\left[\tau_{0}, \tilde{t}_{1}\right]}{\operatorname{argmax}} \sum_{i=1}^{T} w(i, t) \eta\left(i \mid Q^{\prime}\right) .
$$

Let $\Pi_{i}(Q, t)$ denote the foreign firm's profit over all periods when it exports $Q$ in period 1 and is thereafter subject to a total duty, $t$. Define

$$
E_{i}^{0}\left(Q^{\prime}\right) \equiv\left\{t \in B R\left(\eta, Q^{\prime}\right): \Pi_{i}(Q, t)=\Pi_{i}^{*}\right\}
$$

to be the set of best responses of the government which would leave $i$ indifferent between his equilibrium strategy and exporting $Q^{\prime}$. Similarly, the set of sequentially rational AD duties which would make $i$ strictly better off is denoted by

$$
E_{i}\left(Q^{\prime}\right) \equiv\left\{t \in B R\left(\eta, Q^{\prime}\right): \Pi_{i}(Q, t)>\Pi_{i}^{*}\right\}
$$

We say that a sequential equilibrium outcome is $D_{1}$ if and only if there exists an equilibrium giving rise to this outcome which can be supported with beliefs $\eta\left(i \mid Q^{\prime}\right)=0$ at each off equilibrium quantity $Q^{\prime}$ whenever

$$
E_{i}^{0}\left(Q^{\prime}\right) \cup E_{i}\left(Q^{\prime}\right) \subseteq E_{i^{\prime}}\left(Q^{\prime}\right)
$$

for $E_{i^{\prime}}\left(Q^{\prime}\right) \neq\{\emptyset\}$. Thus $D_{1}$ requires the beliefs of the government to place probability zero on type $i$ if whenever $i$ wants to deviate from a particular equilibrium so does $i^{\prime}$. Intuitively, this makes $i^{\prime}$ the more likely type to break the equilibrium.

Note that if $i$ is eliminated for quantity $Q^{\prime}$ using the $D_{1}$ criterion then $Q^{\prime}$ is never a weak best response for that type. The reason is that if $Q^{\prime}$ were a weak best response relative to the equilibria giving rise to the proposed outcome (meaning that $Q^{\prime}$ yields the exporter as much as an equilibrium) then by definition the best response duty against $Q^{\prime}$ must be in $E_{i}^{0}\left(Q^{\prime}\right)$ and hence in $E_{i^{\prime}}\left(Q^{\prime}\right)$. This would make $i^{\prime}$ deviate. Appealing 
once again to the proposition by Kohlberg and Mertens (1986) we could delete such a $Q^{\prime}$ from the strategy set of the exporter of type $i$ without being at risk of eliminating a stable set of the unrestricted game.

The refinement procedure outlined in this section would be useful only if it guarantees the existence of a solution surviving the restrictions. In finite signaling games we can be assured of this by the fact that a stable set of equilibria contains a sequential equilibrium. Hence, if we start the process of elimination with a set of equilibria leading to a stable outcome we will not eliminate this outcome. Since a stable set exists, it follows that we will not eliminate all equilibria.

As is well known, there are a number of refinements of equilibria used in signaling games. Similar to the $D_{1}$ criterion in both intuition and game theory justification are the Intuitive Criterion and the $D_{2}$ criterion (Cho and Kreps, 1987). In general $D_{2}$ is more stringent than $D_{1}$ because it further restricts the strategy spaces of the players. Formally, the steps in applying $D_{2}$ are the same as the ones outlined above for $D_{1}$, except (7) should be replaced with

$$
E_{i}^{0}\left(Q^{\prime}\right) \cup E_{i}\left(Q^{\prime}\right) \subseteq \cup_{i^{\prime} \neq i} E_{i^{\prime}}\left(Q^{\prime}\right)
$$

In our case, $D_{1}$ is sufficient to give rise to a unique stable outcome of the game.

On the other hand, the Intuitive Criterion is a weaker refinement than $D_{1}$. At an out of equilibrium quantity $Q^{\prime}$, the Intuitive Criterion requires assigning probability one to a given type $i$ if, in combination with the lowest possible sequentially rational tariff, $Q^{\prime}$ is (a) preferred by type $i$ to the proposed equilibrium and (b) is not preferred to the proposed equilibrium by any other type. However, the Intuitive Criterion does not provide a systematic way to assign beliefs if at $Q^{\prime}$ more than one type prefers the lowest tariff to the proposed equilibrium.

It is well known that the Intuitive Criterion is not sufficient to support the unique stable equilibrium if there are more than two types even if the profit function of the sender exhibits the single crossing property. ${ }^{16}$ We thus use the $D_{1}$ refinement. Hence, throughout the remainder of the paper when we use terms like "equilibrium" and "outcome" we mean " $D_{1}$ equilibrium" and " $D_{1}$ outcome."

\footnotetext{
${ }^{16}$ See Cho and Kreps (1987) for a discussion of the Spence model with three types.
} 


\section{Solution of the subgame prior to the AD petition}

We will solve for the first stage equilibrium by breaking the problem into several steps. First, we will characterize the foreign firm's isoprofit curves and show that the game falls into a subclass of signaling games with double crossing. Next, we will establish two conditions: a mimicking condition and a condition that in conjunction with the double crossing property implies that the most natural outcome is for all types to pool. Finally, we will describe the behavior of each type in the pooling outcome.

\subsection{Isoprofit curves and the double crossing property}

In the first period a type $i$ exporter knows that upon observing $Q$ the home firm will produce according to its best response function

$$
\tilde{q}=\left(a-Q-c_{d}\right) / 2,
$$

From this point on we adopt the convention that if there is no time superscript we are referring to first period variables.

The equilibrium first period profit of the foreign firm when producing $Q$ is

$$
\pi_{i}(Q)=Q\left(a-Q-2 C_{i}-2 \tau_{0}+c_{d}\right) / 2
$$

The incentive compatible constraint for type $i$ can be constructed by defining an isoprofit curve consisting of combinations of quantities $Q$ and duties $t$ which yield the same total profit, $\bar{\Pi}_{i}$, given that the home firm produces according to its best response, (8). From (9) and (3) the isoprofit curve is implicitly given by

$$
\bar{\Pi}_{i}=\Pi_{i}(Q, t) \equiv \pi_{i}(Q)+(N / 9)\left(a+c_{d}-2 C_{i}-2 t\right)^{2} .
$$

Consider the case when the government has full information. In this case each type $i$ knows that a petition will lead to an $\mathrm{AD}$ duty, $\tilde{t}_{i}-\tau_{0}$. Hence, each type will myopically maximize its first period profit yielding

$$
\widetilde{Q}_{i}=\left(a-2 C_{i}-2 \tau_{0}+c_{d}\right) / 2 \text { and } \widetilde{\pi}_{i}=\left(a-2 C_{i}-2 \tau_{0}+c_{d}\right)^{2} / 8,
$$


and an equilibrium profit over all periods

$$
\Pi_{i}^{s} \equiv\left(a+c_{d}-2 C_{i}-2 \tau_{0}\right)^{2} / 8+(N / 81)\left(a+3 c_{d}-4 C_{i}\right)^{2} .
$$

In Figure 2 we depict the isoprofit curves for three types under the full information outcome. Note that as graphed each firm's preferred set lies to the south of its respective isoprofit curve - for a given quantity, profit increases as the tariff falls.

In standard signaling games it is assumed that one type always has a greater incentive to deviate from a given outcome than another type. This is referred to as the single crossing property since it implies that the isoprofit curves cross only once. We will now show that the isoprofit function of the exporter exhibits a double crossing property. As will become apparent this property will play a key role in solving for the equilibrium of the model. By double crossing we mean

Lemma 1 Any two isoprofit curves $\left\{\bar{\Pi}_{i}, \bar{\Pi}_{j}\right\}, i<j$, can cross at most once in either of the two half-spaces defined by $t=\tau_{0}+Q$. If the isoprofit curves have a point in common along $t=\tau_{0}+Q$, then they are tangent at that point. In other words, the graph of the function $t=\tau_{0}+Q$ divides $(Q, t)$-space in such a way that at any $(Q, t)$ the slope of $\bar{\Pi}_{j}$ is bigger (smaller) (the same as) the slope of $\bar{\Pi}_{i}$ whenever $t>(<)(=) \tau_{0}+Q$.

(All proofs are in the appendix.)

Lemma 1 states that the single crossing assumption is violated in our model. This implies that the incentives for any two types to deviate from a given outcome differ depending on the relative sizes of $t$ and $Q$. Intuitively, the double crossing property reflects the varying incentives to lower current quantity in order to receive a lower duty in the future. On the one hand, high cost firms already produce less than low cost firms and hence do not have to distort their sales as much as low cost firms. Thus, in this respect high cost firms find it easier to deviate from a given outcome (by lowering quantities). On the other hand, low cost firms have more to gain if future duties are lower, and hence they benefit more when today's lower exports result in lower duties tomorrow. Thus, in this respect low cost firms find it easier to deviate from a given outcome. Which incentive dominates depends on the relative sizes of $t$ and $Q$. If $t$ is relatively small the former effect dominates, while if $t$ is relatively large the latter effect dominates. 


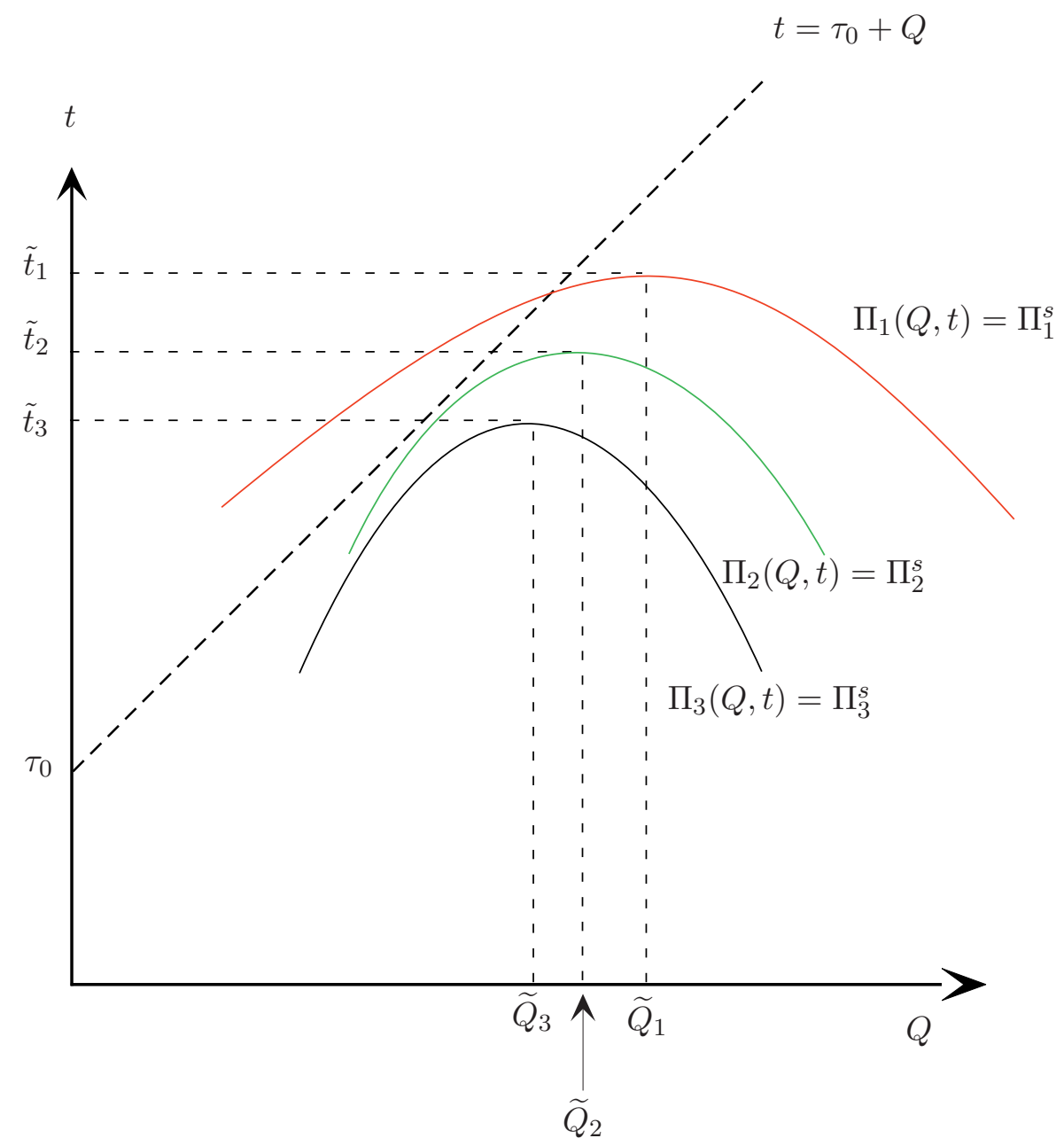

Figure 2: Isoprofit curves under full information 
The double crossing property is graphically depicted in Figure 3. Consider first the case when $Q>t-\tau_{0}$ (i.e., relatively high quantity levels). This case is depicted graphically by point $X$ in Figure 3. At the point of intersection $(X)$ the slope of isoprofit curve for the more efficient type (type 1 ) is bigger than the slope of inefficient type's isoprofit curve. This relationship can simply be interpreted as implying that at $X$ a decrease in exports by 1 is less profitable than a decrease by 2 .

Consider the other case, when $Q<t-\tau_{0}$. This case is depicted by the point $Y$ in Figure 3. At the point of intersection the slope of the isoprofit curve for the efficient type is smaller than the inefficient type's, implying that at $Y$ a decrease in exports by 1 is more profitable than a decrease by 2 .

Finally, if the two isoprofit curves have a point in common along the locus $Q=t-\tau_{0}$, they must be tangent at that point. This case is depicted by the point $Z$ in Figure 5 and will be discussed at greater length in Section 6.3. Hereafter, we will refer to the line $t=\tau_{0}+Q$ as the tangency locus.

Another property of the isoprofit curve is

Corollary 1 Any isoprofit curve can cross the tangency locus at most once.

Corollary 1 implies that an isoprofit curve either never crosses the tangency locus or only crosses the tangency locus once. As will become clear, whether an isoprofit curve crosses the tangency locus depends primarily on the duration of the AD duty.

\subsection{The unique candidate for a pure strategy separating equilibrium}

We begin by deriving the unique candidate for a pure strategy separating equilibrium. In order to support such a solution we must provide each type with a quantity, $Q_{i}^{s}$, which is exported with probability one.

If the outcome is a pure strategy separating equilibrium, then the government is able to infer each type's true cost and will in turn levy the optimal duty, $\tilde{t}_{i}$. This implies that type 1's unique separating sequential equilibrium strategy is to maximize its first period profit myopically, yielding exports of $Q_{1}^{s}=\widetilde{Q}_{1}$ and profit over all periods of $\Pi_{1}^{s}$.

The extent to which types $j>1$ distort exports depends on whether others have a desire to mimic them. If the game is not to be trivial, we must assume that some $i$ is willing to mimic some type $j, i<j$. In general this means $\Pi_{i}^{s}<\Pi_{i}\left(\widetilde{Q}_{j}, \tilde{t}_{j}\right)$. Since 
we are interested in explaining why the most efficient firms restrain their exports, we require that type 1 be willing to mimic 2 ,

$$
\Pi_{1}^{s}<\Pi_{1}\left(\widetilde{Q}_{2}, \tilde{t}_{2}\right)
$$

In Figure 2 we depict a game where (12) is satisfied. As depicted, 2's full information outcome, $\left(\widetilde{Q}_{2}, \tilde{t}_{2}\right)$ lies in 1's strictly preferred region. In other words, as depicted 1 has an incentive to mimic 2 , if doing so could induce an AD duty of only $\tilde{t}_{2}$.

Since $\Pi_{1}^{s}$ is the minimum profit type 1 will earn in any sequential equilibrium, the incentive compatible constraint for type 1 can be defined by the locus of quantity-duty pairs in (10) yielding at least $\Pi_{1}^{s}$

$$
\Pi_{1}^{s} \leq \Pi_{1}(Q, t)
$$

In Figure 2, (13) is satisfied for all $(Q, t)$ lying below $\Pi_{1}^{s}=\Pi_{1}(Q, t)$.

It is easy to verify that (13) implicitly defines a function which is strictly concave in $Q$ and symmetric around $\widetilde{Q}_{1}$. For each $i>1$, (13) defines an open set of quantities around $\widetilde{Q}_{1}, \mathcal{S}_{i}(1)=\left(\underline{Q}_{i}(1), \bar{Q}_{i}(1)\right)$, which type 1 would strictly prefer to its equilibrium strategy if the response was $\tilde{t}_{i}$. The end points of these intervals are

$$
\begin{aligned}
& \underline{Q}_{i}(1)=\widetilde{Q}_{1}-(2 / 9) \sqrt{2 N\left(C_{i}-C_{1}\right)\left(C_{i}+3 c_{d}+a-5 C_{1}\right)}, \\
& \bar{Q}_{i}(1)=\widetilde{Q}_{1}+(2 / 9) \sqrt{2 N\left(C_{i}-C_{1}\right)\left(C_{i}+3 c_{d}+a-5 C_{1}\right)} .
\end{aligned}
$$

Since $C_{1}<C_{i}$ the above quantities are real. In addition, $\mathcal{S}_{i}(1)$ is strictly increasing in $N$, implying that the longer the period the $\mathrm{AD}$ duty stays in effect, the more type 1 is willing to sacrifice if doing so could insure a lower duty. In Figure 3 we depict an incentive compatible quantity set, $\mathcal{S}_{2}(1)$.

Incentive compatibility has several important implications for the behavior of each type $i>1$ in a separating equilibrium. For instance, in any pure strategy sequential separating equilibrium each $i>1$ would be at least restricted to $Q \in \mathcal{S}_{i}^{c}(1)$, where $\mathcal{S}_{i}^{c}(1)$ is defined as the complement of $\mathcal{S}_{i}(1) .{ }^{17}$ Type 2 's possible quantity choices can be further restricted by noting that: $\mathcal{S}_{2}(1)$ is symmetric around $\widetilde{Q}_{1} ; \underline{Q}_{2}(1)<\widetilde{Q}_{2}<$

\footnotetext{
${ }^{17}$ The strategy set of type $i, \mathcal{S}_{i}(h)$, may be further restricted by the incentive compatibility constraint of other types $h, h<i$.
} 


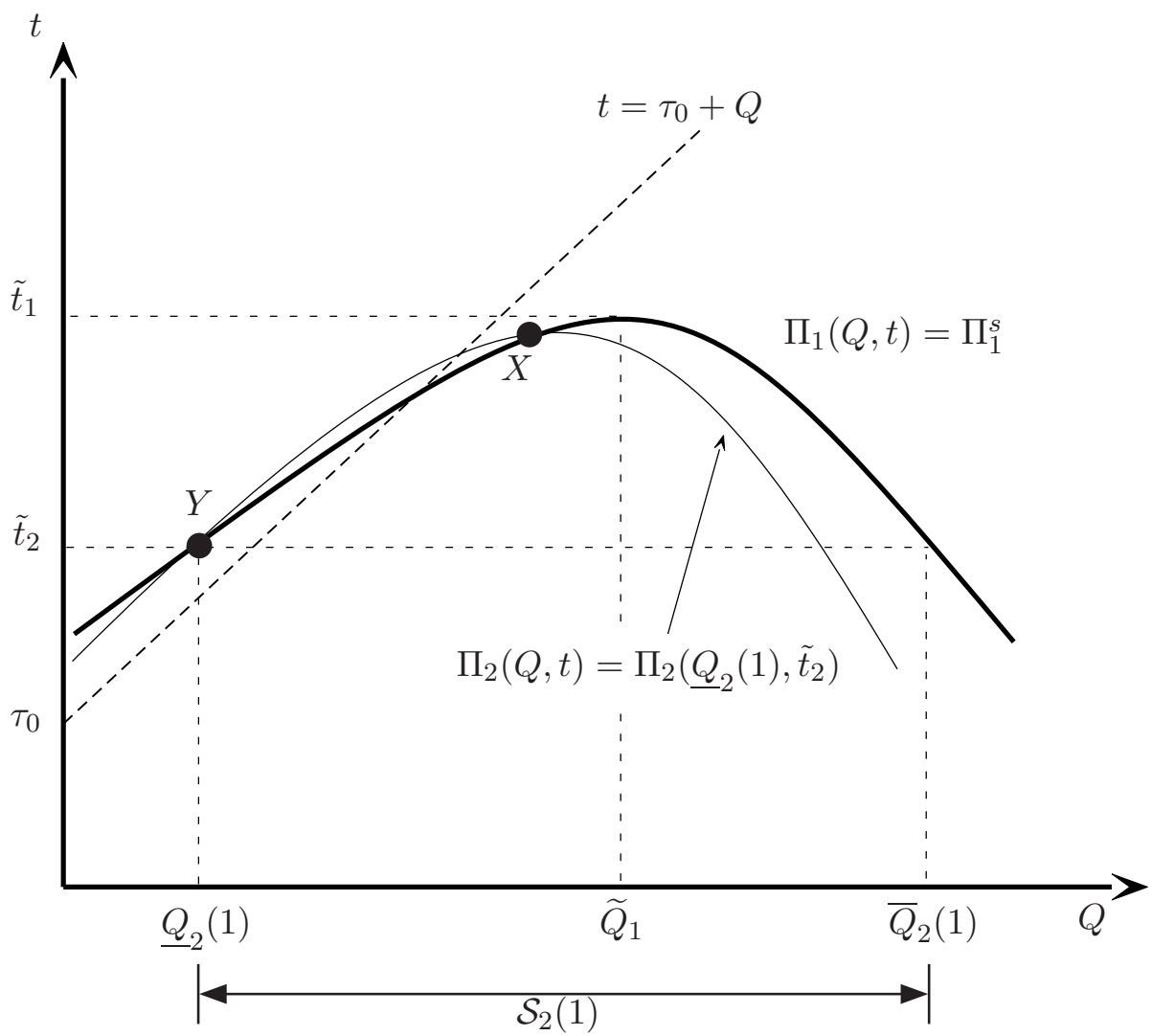

Figure 3: Incentive compatibility constraint for 2 defined by 1 
$\widetilde{Q}_{1}<\bar{Q}_{2}(1)$; and, given $\tilde{t}_{2}$ the profit function of type 2 is symmetric about $\widetilde{Q}_{2}$. These observations imply that the payoff for 2 at $\underline{Q}_{2}(1)$ is higher than at $\bar{Q}_{2}(1)$. Moreover, the fact that 2's profit is monotonically increasing up to $\widetilde{Q}_{2}$ and decreasing thereafter implies that $\underline{Q}_{2}(1)$ is the unique maximizer among the set of quantities available to 2 in a separating equilibrium. Not surprisingly then it is the unique candidate for a self-enforcing separating equilibrium strategy.

Proposition 1 Among the set of separating export levels available to $2, Q_{2}^{s}=\underline{Q}_{2}(1)$ is the unique candidate to emerge in equilibrium.

Denote by $\underline{Q}_{j}(i)$ and $\bar{Q}_{j}(i)$ the end points of the interval $\mathcal{S}_{j}(i), 1 \leq i<j$. $\mathcal{S}_{j}(i)$ is the set of quantities in combination with $\tilde{t}_{j}$ that type $i$ would prefer to $\Pi_{i}^{s}$. We can also show

Corollary $2 Q_{j}^{s}=\min \left\{\underline{Q}_{j}(i)\right\}, 1 \leq i<j$, is the unique candidate for a separating equilibrium strategy for type $j$.

We depict this candidate separating equilibrium in Figure 4. The candidate for separating equilibrium has several nice properties. First, the most efficient exporter does not restrain its exports. Rather, the potential AD duty distorts trade from the less efficient types who voluntarily restrain their exports in order to separate themselves. Second, this candidate equilibrium involves the least amount of trade restraint and as such is the best outcome in the sense of Riley (1979). Finally, this candidate equilibrium has the desirable characteristic that the optimal duties are levied.

However, we can show that if a weak condition regarding the size of the incentive compatibility set is satisfied, this candidate cannot be an equilibrium. This key condition is

$$
\Pi_{1}^{s} \leq \Pi_{1}\left(Q=\tilde{t}_{2}-\tau_{0}, \tilde{t}_{2}\right)
$$

This condition is satisfied in both Figures 3 and 4. We will show in Section 7 that this condition is quite likely to be satisfied. Graphically, the condition implies the point defined by the intersection of $\tilde{t}_{2}$ and the tangency locus, $Q=\tilde{t}_{2}-\tau_{0}$ lies in 1's preferred set. Note also that if (14) is satisfied, then by Corollary 1 all other intersections between the tangency locus and the corresponding optimal duties will also be preferred by 1 . 


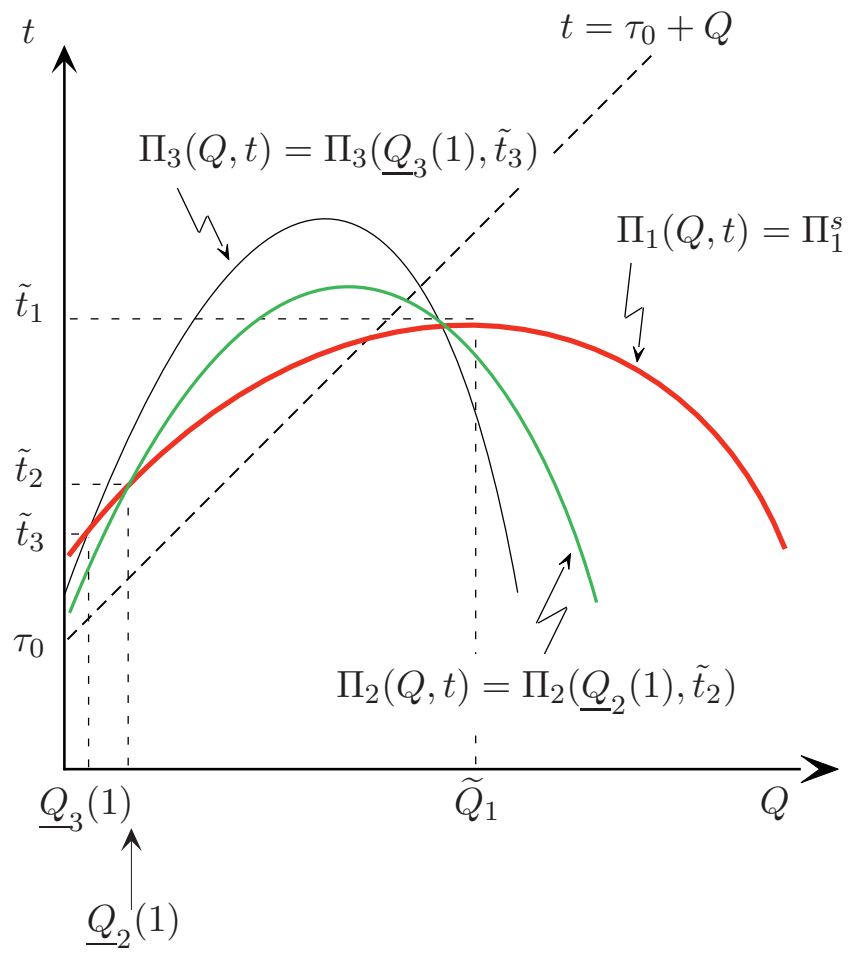

Figure 4: The unique candidate for a separating equilibrium

Proposition 2 If (14) is satisfied, then there does not exist a pure strategy separating equilibrium.

Intuitively, Proposition 2 implies that separating equilibria will not exist whenever 1's desire to avoid optimal AD duties is sufficiently large. If this is the case, complications arising from the double crossing property arise. Consider for instance the candidate equilibrium depicted in Figure 3. Since (14) is satisfied, $\left(Q_{2}^{s}, \tilde{t}_{2}\right)$ must lie in the half-space $Q<t-\tau_{0}$, implying that an increase in exports by 1 is less profitable than an increase by 2 . If the government observes a deviation from the candidate, it infers that the firm is type 2 and hence responds with $\tilde{t}_{2}$. This in turn induces 2 to deviate from the candidate equilibrium. 


\subsection{The unique pooling equilibrium}

Proposition 2 leads us to explore the possibilities for pooling. The next two lemmas will provide the candidate for an equilibrium in which more than one type exports the same quantity and characterize the foreign firm's isoprofit function in the equilibrium.

Lemma 2 Fix a pooling outcome in which more than one type exports $Q^{p}$ with positive probability in the first period, and the response of the government is $t^{p}$. Then it must be that $Q^{p}=t^{p}-\tau_{0}$.

Lemma 2 states that any export-duty pair which does not lie on the tangency locus cannot be a part of a pooling outcome.

We now show that if the indifference curves of two types have a point in common along the tangency line then everywhere else the isoprofit line of the lower type lies above that of the higher type.

Lemma 3 Let $i<j$. Then $\Pi_{i}\left(\hat{Q}=\hat{t}-\tau_{0}, \hat{t}\right)=\Pi_{i}\left(Q^{\prime}, t_{i}\right)$ and $\Pi_{j}\left(\hat{Q}=\hat{t}-\tau_{0}, \hat{t}\right)=$ $\Pi_{j}\left(Q^{\prime}, t_{j}\right)$ imply $t_{j}<t_{i}$.

Figure 5 is useful for clarfying Lemma 3. Consider a point, say $Z$, on the tangency locus. By Lemma 1 we know that any two isoprofit curves through $Z$ must be tangent. For example, in Figure 5 we have drawn three isoprofit curves containing $Z$. Lemma 3 implies that the isoprofit curves of the higher types are nested within the isoprofit curve of the lower types. For instance, 3's isoprofit curve lies within 2's which in turn lies within 1's isoprofit curve. Lemma 3 is important since it implies that the government can clearly rank each type's incentive to deviate from a candidate on the tangency locus. In particular, at $Z$ a small deviation is most profitable for 1 .

Using Lemma 3 we can also show

Corollary 3 If type $i$ pools with positive probability in a sequential equilibrium then every type $j>i$ exports the pooled quantity with probability one.

We are now ready to prove our main proposition. In particular, we now show that if (14) is satisfied, then there is a unique equilibrium in which the $\mathrm{AD}$ threat induces all types to sell the same quantity, which means that the most efficient types voluntarily restrain their exports in order to receive a lower $\mathrm{AD}$ duty. 
Proposition 3 If (14) is satisfied, then there exists a unique equilibrium in which type 1 produces the pooled quantity with positive probability and all other types pool with probability one.

Figure 5 depicts the unique pure pooling equilibrium. Several comments are warranted. First, unlike the separating candidate, in the pure pooling equilibrium the most efficient firm voluntarily restricts its output prior to the $\mathrm{AD}$ investigation. In fact, it is generally the case that exports are restrained not just by 1 but by many of the more efficient types. Thus, the pooling equilibrium is consistent with the empirical evidence (discussed in Section 2) that the threat of an AD duty induces VERs by most efficient foreign competitors.

Second, depending on the probability distribution $\mu$, cost-based AD can easily result in the perception that inefficient exporters are more threatening than they actually are. For instance as depicted, all types $i>1$ will receive a higher duty than is optimal. This prediction is again consistent with the empirical evidence. In the steel industry, for instance, a large number of cases have been filed against relatively inefficient producers. This perception was most forcefully asserted during the Uruguay Round negotiations as representatives from developing countries (i.e., relatively inefficient firms) vigorously negotiated for changes in the rules governing cost-based AD.

Third, these distortions imply that domestic consumers get the worst of both worlds. Prior to the $\mathrm{AD}$ investigation consumers suffer as the efficient firms restrict output. Following the investigation, consumers bear the burden of having overly large AD duties being levied on inefficient firms.

\subsection{A necessary and sufficient condition}

Before concluding this section we would like to relax condition (14) and give a necessary and sufficient condition for the unique equilibrium to involve pooling in exports (not necessarily by all types) and characterize the outcome. The condition requires type $T-1$ to prefer the point $\left(Q=\tilde{t}_{T}-\tau_{0}, \tilde{t}_{T}\right)$ to its unique candidate separating equilibrium strategy.

Intuitively, this is the case because Lemma 1 guarantees that if $T-1$ prefers to separate rather than mimic $T$ at $\left(Q=\tilde{t}_{T}-\tau_{0}, \tilde{t}_{T}\right)$, then so will every lower type. Consequently, the separating equilibrium isoprofit curves of each lower type lie in the 
right half space defined by the tangency locus. The unique equilibrium of the game will be in pure strategies where each lower type exports a quantity defined in Corollary 2.

Proposition 4 There exists a unique outcome of the game which involves all but (possibly) the lowest types exporting the same quantity with positive probability if and only if $\Pi_{T-1}^{s} \leq \Pi_{T-1}\left(Q=\tilde{t}_{T}-\tau_{0}, \tilde{t}_{T}\right)$.

Proposition 3 gives a sufficient condition for type 1 to voluntarily restrict exports in equilibrium. Proposition 4 provides a necessary condition for a type $i$ to participate in a pool. By replacing $i$ with 1 in the construction of the unique pooling equilibrium we see that the most efficient type will restrict exports only if $\Pi_{1}^{s}>\Pi_{1}\left(Q=\tilde{t}_{T}-\tau_{0}, \tilde{t}_{T}\right)$.

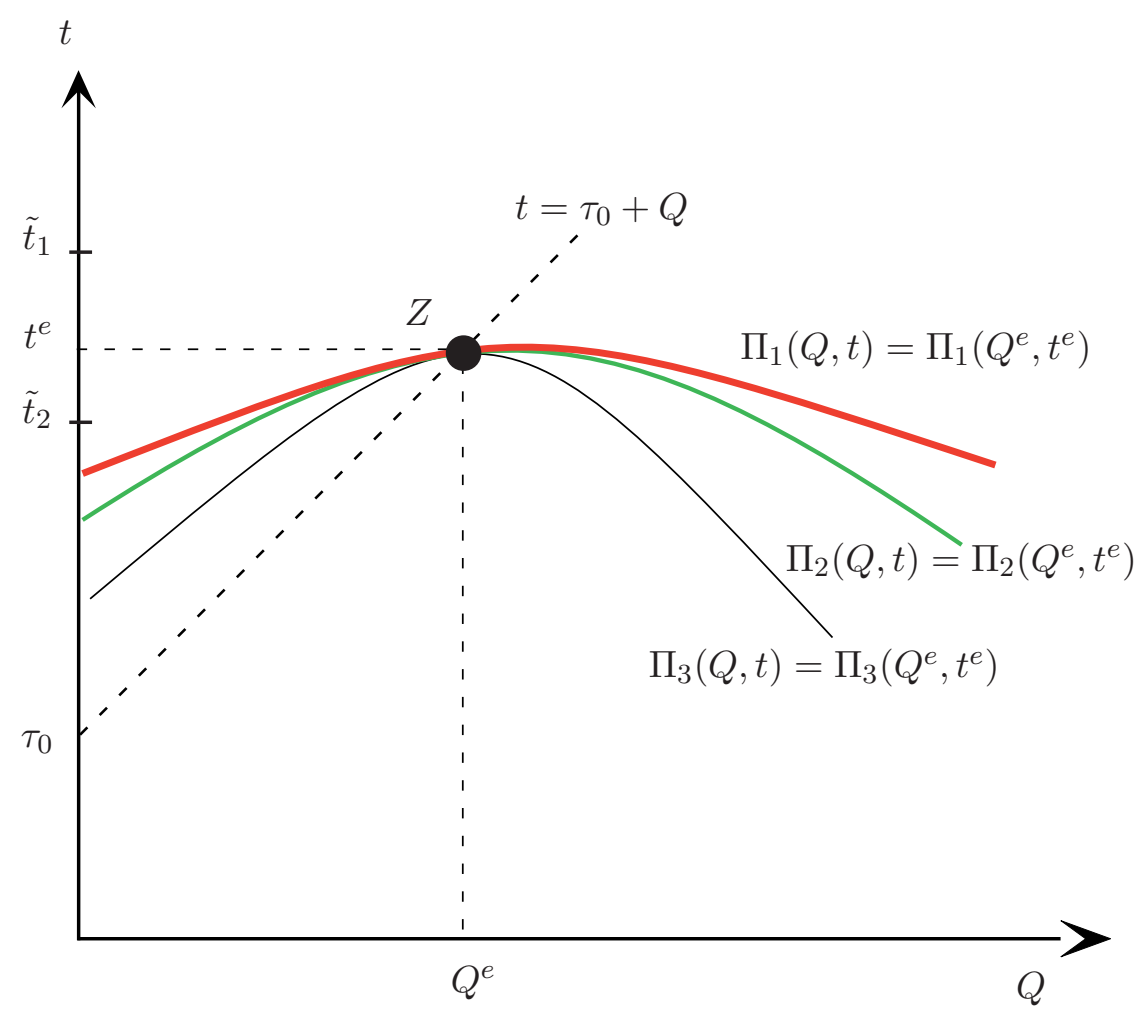

Figure 5: The unique pooling equilibrium 


\section{Characterization of the pooling condition}

We have argued above that if (14) holds, then pooling is the unique equilibrium. In this section we will relate this condition to the underlying primitives of the model. For analytical convenience we will now assume that the foreign firm is one of two possible types, 1 and 2. We will also assume that $c_{d}=C_{2}$ and that $\tau_{0}=\tilde{t}_{2}$.

First, we want to establish that the mimicking condition (12) holds. Substituting we can show that 1 would like to mimic 2 if

$$
N>N^{m} \equiv \frac{81(A-1)}{8(5 A-4)}
$$

where we have defined relative costs as

$$
A \equiv \frac{a-C_{1}}{a-C_{2}}>1
$$

In Figure 6 we graph the mimicking condition in $A-N$ space. The mimicking condition is satisfied for all points lying above the $N^{m}$ contour. As the graph makes clear, for all $N>1$ the mimicking condition holds for all reasonable values of $A$. For $N=1$ the condition only holds for $A \in(1,49 / 41)$. Recall that when a firm restrains exports to $\widetilde{Q}_{2}$ some first period profit is sacrificed. If the game is sufficiently short, the gain from the lower duty is insufficient to induce mimicking. In current U.S. practice, duties are rarely removed sooner than two years after being imposed. Given this practice we believe that the relevant scenario is when the the $\mathrm{AD}$ duty stays in effect for longer than one period and thus that the mimicking condition holds for all values of $A$.

Conditional on (12), the question now is whether (14) is satisfied. Substituting, we can show that the pooling condition holds if

$$
N>N^{p} \equiv \frac{9(6 A-5)^{2}}{32(5 A-4)(A-1)}
$$

This sufficient condition is also graphed in Figure 6 and is satisfied for all points lying above the $N^{p}$ contour. The graph shows that the pooling condition is likely to hold for most reasonable parameter values. In particular, if the duty is levied for at least several periods, the condition is satisfied for almost all $A$. For instance, if $N=3$, the condition holds for all $A>1.284$, if $N=5$, the condition holds for all $A>1.093$, 


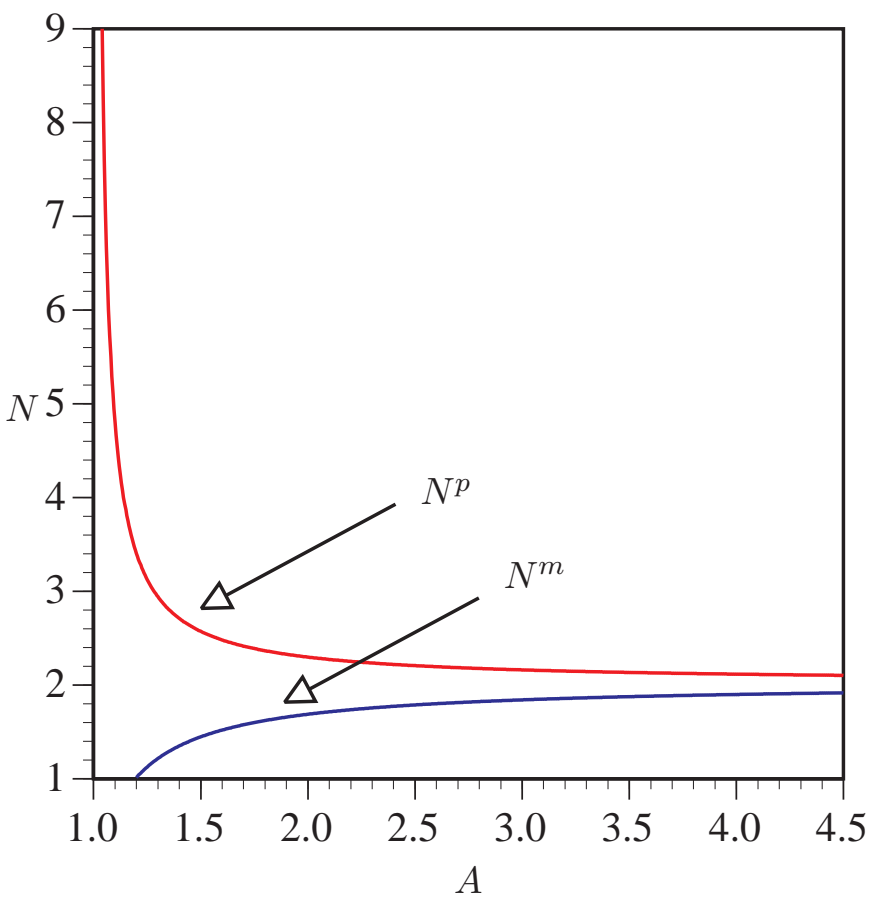

Figure 6: $N^{m}$ and $N^{p}$ contours 
and if $N=10$, the condition holds for all $A>1.035$.

While the precise values are clearly specific to this example, this exercise does illustrate the two general insights. First, the longer is the duration of the post-duty game, the more likely will the pooling outcome emerge. Second, post-duty game does not have to be particularly lengthy for pooling to emerge. A review of U.S.'s experience reveals that $\mathrm{AD}$ duties are often quite long-lived. For instance, in the U.S. duties have been in place for at least 10 years in more than $20 \%$ of (affirmative) AD cases; in fact, according to ITC (1995), more than half of the AD duties levied between 1955 and 1991 were still in effect in 1991. Thus, the model's prediction that foreign firms restrain exports in order to reduce potential $\mathrm{AD}$ duties seems plausible.

\section{Welfare implications}

We would like to conclude our discussion by conducting a simple welfare analysis. As we did in the previous section we will assume that the foreign firm is one of two possible types, 1 and 2 . The prior probability of type 1 is $\mu$. We will continue to assume that $c_{d}=C_{2}$ and that $\tau_{0}=\tilde{t}_{2}$.

We compare the expected welfare in the pure strategy pooling equilibrium with a situation in which the government does not have a cost-based AD mechanism. In keeping with GATT MFN rules, we thus consider an alternative where exporters are subject to a uniform tariff. ${ }^{18}$

In a pure strategy pooling equilibrium the government levies a duty equal to $t^{e}-\tau_{0}$ where $t^{e}=\mu \tilde{t}_{1}+(1-\mu) \tilde{t}_{2}$. Regardless of the firm's type, first period exports are $Q^{e}=t^{e}-\tau_{0}$ and the domestic firm maximizes its profit taking $Q^{e}$ as given. In subsequent periods the welfare results from the unique Cournot equilibrium with the AD duty imposed.

If the government does not have $\mathrm{AD}$ law and commits to $\tau_{0}$, the welfare would be calculated from the unique Stackelberg and Cournot equilibria in first and later periods, respectively.Using our expression for relative costs $(A)$, the difference between the expected equilibrium welfare and the ex-ante expected welfare from precommitment

\footnotetext{
${ }^{18}$ The unique ex-ante optimum duty is easily seen to be $\mu \tilde{t}_{1}+(1-\mu) \tilde{t}_{2}$. We can perform the welfare analysis with this tariff imposed in all periods, but we want to emphasize that even with suboptimal tariffs (and maybe even the worst ex ante tariff) the country is still better off without an antidumping law.
} 
can be shown from (4) and (5) to be

$$
\Delta(N, A, \mu)=(1 / 72)(4 N+11)(A-1)^{2} \mu^{2}-(1 / 72)(27 A-14)(A-1) \mu-7 / 288 .
$$

$\Delta(\cdot)$ is increasing with $N$, implying that the longer the duration of the duty the larger are the losses due to a commitment to a suboptimal duty.

In Figure 7 we depict the zero contours of $\Delta(\cdot)$ for $N=5$ and $N=10$. Cost-based AD raises welfare in the region lying above the contour. The intuition is quite clear: costbased $\mathrm{AD}$ raises welfare the more likely the firm is type 1 (higher $\mu$ ) and the longer the duration of the duty (larger $N$ ). However, note that if the duty stays on for 5 periods, the cost difference between the firms must get quite large before the $\mathrm{AD}$ policy raises welfare. $\Delta(\cdot)$ is positive for a substantial region of the parameter space only for $N=10$.

These results along with those in the previous section highlight the importance of the duration of the duties. This insight makes the Uruguay Round's sunset amendment particularly relevant. This provision mandates that AD duties must be reviewed after five years and the duty should be removed unless there is evidence that doing so will result in injury. The sunset amendment was designed to limit the attractiveness of $\mathrm{AD}$ actions (to domestic industries) and as such this provision should raise welfare. Surprisingly, we find that it may well exacerbate the costs of cost-based AD policy.

\section{Concluding Comments}

By most accounts the downward trend in trade restrictions was halted (or at least slowed) in the mid-1970s (Bhagwati, 1988; Krueger, 1995). Blame is usually pointed to the combination of high-track (VERs) and low-track (AD duties) restraints. In this paper we have demonstrated that both phenomena can be explained by the fact that AD laws were broadened to allow for cost-based allegations in the mid-1970s. We have shown that VERs are undertaken to discourage cost-based AD complaints. However, we find that in general the VER does not completely release the protectionist pressures but rather causes the duties to be clumsily levied.

Our results also help explain why all concerned parties-domestic firms, foreign firms, and consumers - are unhappy with AD protection. Domestic industries complain that $\mathrm{AD}$ does not sufficiently protect them against their most feared foreign competitors 


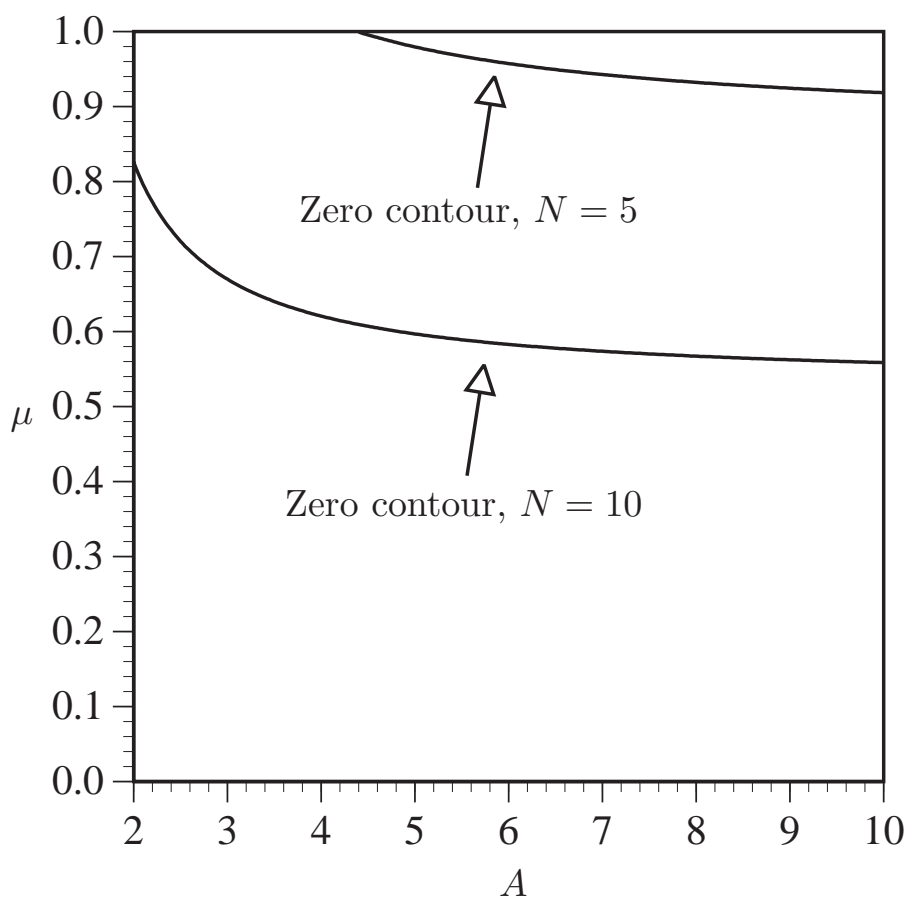

Figure 7: Zero contour of $\Delta(N, \mu, A)$ 
(Stewart, 1991). At the same time, foreign firms often gripe that the duties are excessive. Our model shows that both charges have validity. The VER distorts the government's perception of the the foreign firm's efficiency and leads to undesirably low (high) duties on efficient (inefficient) competitors. Cost-based duties would be more efficiently levied if the VERs did not interfere with the government's ability to perceive costs. Finally, consumers suffer due to both the anticipatory VER and to the ineptly determined duty. Our results provide additional evidence that AD law creates a heavy burden on consumers. All in all, even though cost-based AD raises welfare under complete information, the distortions inherent with implementing it under incomplete information make it an undesirable policy - especially if the duties are levied for relatively short durations. Thus, GATT/WTO parties would be well served to couple the recent sunset provision with additional restrictions on cost-based allegations.

From a technical perspective, our results highlight the importance of the single crossing assumption in economic models. While this assumption is usually imposed, our model suggests that those interested in accurately depicting the outcomes in signaling games should formally model agents' payoffs, i.e., derive payoffs from more basic economic primitives. As we have shown the equilibrium depends crucially on whether the payoffs satisfy single crossing or double crossing.

\section{References}

Anderson, James E., 1992, Domino Dumping, I: Competitive Exporters, American Economic Review; 82(1), March, 65-83.

Anderson, Keith B., 1993, Antidumping laws in the United States: Use and welfare consequences, Journal of World Trade; 27, April.

Bagwell, Laurie Simon and B. Douglas Bernheim 1996, Veblen Effects in a Theory of Conspicuous Consumption, American Economic Review, 86(3) 349-73.

Baldwin, Robert E., 1989, The Political Economy of Trade Policy, Journal of Economic Perspectives, 3(4), 119-35.

Banks, J.S. and J. Sobel, 1987, Equilibrium selection in signaling games, Econometrica $55,647-661$. 
Bellis, Jean-François. 1989, The EEC antidumping system, in Jackson, John H. and Edwin A. Vermulst, eds., Antidumping Law and Practice, (The University of Michigan Press).

Bernheim, B. Douglas, 1991, Tax Policy and the Dividend Puzzle, Rand Journal of Economics 22(4), 455-76.

Bernheim, B. Douglas, 1994, A Theory of Conformity, Journal of Political Economy 102(5), 841-77.

Bhagwati, Jagdish, 1988, Protectionism, (MIT Press: Cambridge).

Boltuck, Richard and Robert E. Litan, 1991, Down in the Dumps, (The Brookings Institution, Washington, DC).

Braga, C.A.P. and S.D. Silber, 1993, Brazilian frozen concentrated juice: The folly of unfair trade cases, in J.M. Finger, ed., Antidumping: How it works and who gets hurt, (University of Michigan Press: Ann Arbor).

Brander, J.A. and B.J. Spencer, 1984, Tariff protection and imperfect competition, in H. Kierzkowsky, ed., Monopolistic competition and international trade, (Clarendon, Oxford) 194-206.

Cho, I.K. and D.M. Kreps, 1987, Signaling games and stable equilibria, Quarterly Journal of Economics 42, 179-221.

Cho, In-Koo, 1987, A refinement of sequential equilibrium, Econometrica 55, 1367-1389.

Cho, In-Koo, 1993, Strategic stability in repeated signaling games, International Journal of Game Theory, 22, 107-121.

Cho, In-Koo, 1994, Separation or Not: A Critique of "Appearance-Based" Selection Criteria, Seoul Journal of Economics 7(3), 249-68.

Cho, I.K. and D.M. Kreps, 1987, Signaling games and stable equilibria, Quarterly Journal of Economics 42, 179-221.

Cho, I.K. and J. Sobel, 1990, Strategic stability and uniqueness in signaling games, Journal of Economic Theory, 50, 381-413.

Clarida, Richard H., 1993, Entry, dumping, and shakeout, American Economic Review 83, 180-202.

Clarida, Richard H., 1996, Dumping in theory, in policy and in practice, in J. Bhagwati and R. Hudec, eds., Fair Trade and Harmonization, (MIT Press, Cambridge) 357-389. 
Ethier, W., 1982, Dumping, Journal of Political Economy 90, 487-506.

Feenstra, Robert C. and Tracy R. Lewis, 1991, Negotiated Trade Restrictions with Private Political Pressure, Quarterly Journal of Economics, 106(4), 1287-1308.

Fudenberg, D. and J. Tirole, 1992, Game theory, (MIT Press).

Hansen, Wendy L. and T.J. Prusa, 1995, The road most taken: The rise of Title VII protection, The World Economy, 18(2), 295-313.

Harris, R., 1985, Why voluntary export restraints are "voluntary", Canadian Journal of Economics, 18, 799-809.

Hillman, Arye L. and Heinrich W. Urspring, 1988, Domestic Politics, Foreign Interests and International Trade Policy, American Economic Review, 77(4), 729-45.

Hoekman, B. and M.P. Leidy, 1991, Antidumping for services?, in Tharakan, P.K.M., ed., Policy Implications of Antidumping Measures, (North-Holland).

Horlick, Gary N. 1989, The United States antidumping system, in Jackson, John H. and Edwin A. Vermulst, eds., Antidumping Law and Practice, (The University of Michigan Press).

International Trade Commission, 1995, The Economic Effects of Antidumping and Countervailing Duty Orders and Suspension Agreements, Publication Number 2900, (International Trade Commission, Washington, DC).

Jones, K., 1986, World industry studies 4. Politics vs economics in world steel trade, (Allen \& Unwin, London).

Kohlberg, E. and J-F. Mertens, 1986, On the strategic stability of equilibria, Econometrica 54, 1003-1038.

Kreps, D.M. and J. Sobel, 1994, Signaling, in R.J. Aumann and S. Hart, eds., Handbook of game theory, Vol. 2 (North-Holland, Amsterdam) 849-867.

Kreps, D.M. and R. Wilson, 1982, Sequential equilibria, Econometrica 50, 863-894.

Krishna, K., 1989, Trade restrictions as facilitating practices, Journal of International Economics, 26, 251-270.

Krueger, A.O., 1995, The american trade policy: A tragedy in the making, (The AEI Press, Washington, D.C.).

Low, P., 1993, Trading free: The GATT and U.S. trade policy, (The Twentieth Century Fund Press, New York). 
Mendez, J.A., 1993, The development of the Columbian cut flower industry: A textbook example of how a market economy works, in J.M. Finger, ed., Antidumping: How it works and who gets hurt, (University of Michigan Press: Ann Arbor).

Messerlin, Patrick, 1989, The EC antidumping regulations: A first economic appraisal, 1980-85, Weltwirtschaftliches Archiv, 125, 563-87.

Milgrom, Paul and Roberts, John D., 1982, Limit Pricing and Entry under Incomplete Information: An Equilibrium Analysis Econometrica, 50(2), 443-59.

Murray, Tracy, 1991, The administration of the antidumping duty law by the Department of Commerce, in Richard Boltuck and Robert E. Litan, eds., Down in the Dumps, (The Brookings Institution, Washington, DC), 23-56.

Patrick, H. and H. Sato, 1982, The political economy of United States-Japan trade in steel, in Yamamura, K. ed., Policy and trade issues of the Japanese economy: American and Japanese perspectives, (University of Washington Press).

Prestowitz, Clyde. 1988, Trading places: How we are giving our future to Japan and how to reclaim it, (Basic Books, New York).

Prusa, Thomas J., 1992, Why are so many antidumping petitions withdrawn?, Journal of International Economics 33, 1-20.

Riley, John 1979, Informational Equilbrium, Econometrica, 47, 331-59.

Rosendorff, B. Peter, 1996, Voluntary Export Restraints, Antidumping Procedure, and Domestic Politics, American Economic Review, 86(3) 544-561.

Staiger, Robert W. and Frank A. Wolak, 1989, Strategic use of antidumping law to enforce tacit international collusion, NBER working paper, No. 3016.

Staiger, Robert W. and Frank A. Wolak, 1992, The effect of domestic antidumping law in the presence of foreign monopoly, Journal of International Economics 32, 265-87.

Stewart, Terrence, 1991, Administration of the antidumping duty law: A different persective, in Richard Boltuck and Robert E. Litan, eds., Down in the Dumps, (The Brookings Institution, Washington, DC), 288-330.

van Damme, E., 1987, Stability and perfection of Nash equilibria, (Springer-Verlag, Berlin). 


\section{Appendix}

\section{Proof of Lemma 1}

Implicit differentiation of $(10)$ at any $(Q, t)$ yields a slope of an isoprofit curve given by

$$
\sigma(Q, t)=\frac{d t}{d Q}=\left(\frac{9}{8 n}\right)\left(\frac{a-2 Q-2 C_{i}-2 \tau_{0}+c_{d}}{a-2 t-2 C_{i}+c_{d}}\right) \text {. }
$$

The first part of the claim follows directly from the definition of $\sigma(Q, t)$ and monotonocity of the profit function. The second part of the claim follows from differentiating $\sigma(Q, t)$ with respect to $C_{i}$ at any $(Q, t)$.

\section{Proof of Corollary 1}

If the isoprofit curve of type $i$ crossed the tangency locus twice then continuity would imply that $i$ must have another isoprofit curve tangent to $t=\tau_{0}+Q$ at a point $(\hat{Q}=$ $\left.\hat{t}-\tau_{0}, \hat{t}\right)$. Lemma 1 shows that an isoprofit curve of any $i^{\prime}$ through $\left(\hat{Q}=\hat{t}-\tau_{0}, \hat{t}\right)$ would be tangent also and both curves would lie in the same half space defined by $t=\tau_{0}+Q$ at least in a $\epsilon$-neighborhood of $\left(\hat{Q}=\hat{t}-\tau_{0}, \hat{t}\right)$. Since profit is continuous we can always find a sufficiently small $\delta$-perturbation of the payoff of one type so that the isoprofit curves cross twice within $\epsilon$ of $\left(\hat{Q}=\hat{t}-\tau_{0}, \hat{t}\right)$. This would violate Lemma 1.

\section{Proof of Proposition 1}

Fix a sequential separating equilibrium outcome obtained from 2 exporting $Q^{*} \in \mathcal{S}_{2}^{c}(1)$, $Q^{*} \neq \underline{Q}_{2}(1)$, and 1 exporting $\widetilde{Q}_{1}$. Take an out of equilibrium message $Q^{\prime} \in \mathcal{S}_{2}^{c}(1)$ such that $\left|\widetilde{Q}^{*}-\widetilde{Q}_{1}\right|>\left|Q^{\prime}-\widetilde{Q}_{1}\right|$.

Let us construct the sets of sequentially rational responses of the government to $Q^{\prime}$ which would make each type break the equilibrium. By the definition (incentive compatibility) of $\mathcal{S}_{2}(1)$ no duty $t \in\left[\tilde{t}_{2}, \tilde{t}_{1}\right]$ would make 1 deviate from $\widetilde{Q}_{1}$ to $Q^{\prime}$. Continuity and monotonicity of 2's profit function guarantee that exporting $Q^{\prime}$ would be strictly preferred to $Q^{*}$ if that would make the country impose $\tilde{t}_{2}$ (or any lower duty). Hence,

$$
E_{1}^{0}\left(Q^{\prime}\right) \cup E_{1}\left(Q^{\prime}\right) \subseteq E_{2}\left(Q^{\prime}\right)
$$

and the $D_{1}$ criterion requires the beliefs of the government to place probability zero on 
1 at $Q^{\prime}$. Hence at $Q^{\prime}$ we must have the posterior restricted to $\left.\eta\right|_{i \geq 2}$, where

$$
\left.\eta\right|_{i \geq j}\left(i^{\prime} \mid Q\right)=\left\{\begin{array}{ll}
\frac{\eta\left(i^{\prime} \mid Q\right)}{\sum_{i \geq j} \eta(i \mid Q)} & , \text { if } i^{\prime} \geq j \\
0 & , \text { otherwise }
\end{array} .\right.
$$

Since the best reply of the government is decreasing in its beliefs this would make 2 defect from the equilibrium.

We could make the same argument for all $Q^{*} \neq \underline{Q}_{2}(1)$. Hence the unique candidate separating $D_{1}$ equilibrium outcome is the one arising from type 2 exporting $\underline{Q}_{2}(1)$.

\section{Proof of Corollary 2}

Note that the strict concavity of the separating equilibrium isoprofit curve for type 1 implies that $\bar{Q}_{j}(1)>\bar{Q}_{i}(1)$ for $j>i>1$. On the other hand, Lemma 1 implies that $\Pi_{i}\left(\bar{Q}_{i}(1), \tilde{t}_{i}\right)>\Pi_{i}\left(\bar{Q}_{j}(1), \tilde{t}_{j}\right)$. Hence $\bar{Q}_{j}(1)>\bar{Q}_{j}(i), \forall j>i>1$ and each type $j$ is constrained only by type 1 at high quantity levels.

Starting with type 3 , for each type $j \geq 3$ apply the arguments used in Proposition 1 to show that any quantity $Q^{\prime}>\bar{Q}_{j}(1)$ in combination with $\tilde{t}_{j}$ is inferior to $\bar{Q}_{j}(1)$. This is the case because the $D_{1}$ criterion concentrates the beliefs of the government on $k \geq j$ and the corresponding best response would make $j$ deviate from $Q^{\prime}$.

Fix a candidate equilibrium in which each type $j$ exports $\bar{Q}_{j}(1)$. To see that $\bar{Q}_{j}(1)$ is not a stable equilibrium we use Lemma 1 once again to claim that

$$
E_{1}^{0}\left(\bar{Q}_{j}(1)-\epsilon\right) \cup E_{1}\left(\bar{Q}_{j}(1)-\epsilon\right) \subseteq E_{j}\left(\bar{Q}_{j}(1)-\epsilon\right)
$$

Since $\Pi_{j}\left(\bar{Q}_{j}(1), \tilde{t}_{j}\right)>\Pi_{j}\left(\bar{Q}_{j-1}(1), \tilde{t}_{j-1}\right), D_{1}$ requires that the response of the government at $\bar{Q}_{j-1}(1)-\epsilon$ be at most $\tilde{t}_{j-1}$ which is sufficient to discard $\bar{Q}_{j-1}(1)$ as a candidate equilibrium.

Proposition 1 showed that the unique candidate for a $D_{1}$ strategy for 2 is $Q_{2}^{s}=\underline{Q}_{2}(1)$. Let $\hat{\hat{Q}}=\min \left\{\underline{Q}_{3}(1), \underline{Q}_{3}(2)\right\}$. Then both type 1 and type 2 are content with separation

rather than mimic type 3 at $Q^{\prime}<\hat{\hat{Q}}$ and get $\tilde{t}_{3}$. Hence $D_{1}$ would restrict the beliefs of the government to $i \geq 3$ at $Q^{\prime}+\epsilon<\hat{\hat{Q}}$ and the sequentially rational tariff would make 3 deviate from $Q^{\prime}$. The arguments for all other types are identical.

\section{Proof of Proposition 2}


Proposition 1 implies that it is sufficient to prove that $\underline{Q}_{2}(1)$ is not a $D_{1}$ strategy for 2 . Let us fix the outcome arising from 2 exporting $\underline{Q}_{2}(1)$. By construction $\underline{Q}_{2}(1)<\tilde{t}_{2}-\tau_{0}$, which guarantees that the isoprofit curve of 2 through $\left(\underline{Q}_{2}(1), \tilde{t}_{2}\right)$ has a slope which is bigger than the corresponding slope for type 1 (by Lemma 1). This implies that for $Q^{\prime}$ $\epsilon$-bigger than $\underline{Q}_{2}(1)$ the set of sequentially rational duties weakly preferred to $\left(\underline{Q}_{2}(1), \tilde{t}_{2}\right)$ by 1 in combination with $Q^{\prime}$ is a subset of the best responses which 2 strictly prefers to its equilibrium action. If the given equilibrium produces a $D_{1}$ outcome we should be able to support it with beliefs $\left.\eta\right|_{i \geq 2}$ at $Q^{\prime}$. Hence the best response of the government is at most $\tilde{t}_{2}$. Since, with any $t \leq \tilde{t}_{2}$ fixed, the profit of 2 is monotonically increasing in $Q$ at $\underline{Q}_{2}(1)$, type 2 would deviate to $Q^{\prime}$, thus upsetting the unique candidate for a $D_{1}$ pure strategy separating equilibrium outcome.

\section{Proof of Lemma 2}

Without loss of generality assume that $Q^{p}<t^{p}-\tau_{0}$. Let $i$ be the highest type in the pool. Then $t^{p}>\tilde{t}_{i}$. Lemma 1 guarantees that in a $D_{1}$ equilibrium the beliefs of the government at $Q^{\prime} \epsilon$-smaller than $Q^{p}$ should place $\eta\left(i^{\prime} \mid Q^{\prime}\right)=0$ for all $i^{\prime}<i$. Hence the response of the government at $Q^{\prime}$ should be less than or equal to $\tilde{t}_{i}$. Continuity of the exporter's payoff in $Q^{\prime}$ would make $i$ strictly better off deviating from the pool for sufficiently small $\epsilon$.

\section{Proof of Lemma 3}

In Corollary 2 we established that any point $\left(\hat{Q}=\hat{t}-\tau_{0}, \hat{t}\right)$ is the unique intersection of the tangency locus with the isoprofit function $\Pi_{j}(\hat{Q}, \hat{t})=\Pi_{j}(Q, t)$ so that any $Q^{\prime}<\hat{Q}$ and $t^{\prime}$ such that $\Pi_{j}(\hat{Q}, \hat{t})=\Pi_{j}\left(Q^{\prime}, t^{\prime}\right)$ implies $t^{\prime}>Q^{\prime}+\tau_{0}$.

Assume that at $Q^{\prime}<\hat{Q}, \Pi_{i}(\hat{Q}, \hat{t})=\Pi_{i}\left(Q^{\prime}, t_{i}\right)$ and $\Pi_{j}(\hat{Q}, \hat{t})=\Pi_{j}\left(Q^{\prime}, t_{j}\right)$ with $t_{j}>t_{i}$, so that the isoprofit curve of $j$ through $(\hat{Q}, \hat{t})$ is above that of $i$. We will show that this assumption leads to a contradiction. By monotonicity of the profit in $t$ we have

$$
\Pi_{i}(\hat{Q}, \hat{t})=\Pi_{i}\left(Q^{\prime}, t_{i}\right)>\Pi_{i}\left(Q^{\prime}, t_{j}\right) .
$$

On the other hand, since $t_{j}>\tau_{0}+Q^{\prime}$, Lemma 1 shows that the slope of $j$ 's isoprofit curve through $\left(Q^{\prime}, t_{j}\right)$ is bigger than the corresponding slope for $i$. This implies that

$$
\Pi_{i}(\hat{Q}, \hat{t}) \geq \Pi_{i}\left(Q^{\prime}, t_{j}\right) \Rightarrow \Pi_{j}(\hat{Q}, \hat{t})>\Pi_{j}\left(Q^{\prime}, t_{j}\right)
$$


The last statement contradicts (A.1) and the construction of $t_{j}$ as $\Pi_{j}(\hat{Q}, \hat{t})=\Pi_{j}\left(Q^{\prime}, t_{j}\right)$. Similar arguments hold for $Q^{\prime}>\hat{Q}$.

\section{Proof of Corollary 3}

Suppose that $i$ is the lowest type in the pool and $j>i$ randomizes in equilibrium between some $Q$ and the pooled quantity $Q^{p}$. Then $j$ must be indifferent between $Q$ and $Q^{p}$. Since the equilibrium isoprofit curve of $i$ is everywhere above that of $j$ according to Lemma 3 , it must be that $Q$ is strictly preferred to the equilibrium by $i$ in combination with the equilibrium tariff of the government at $Q$. This would break the pool.

\section{Proof of Proposition 3}

By Proposition 2 (and the remarks following) no type can separate from type 1 in a $D_{1}$ equilibrium. Moreover, Lemma 1 guarantees that if type 1 weakly prefers a point along the tangency line to a given point $(Q, t)$ then every higher type strictly prefers the point along $t=\tau_{0}+Q$ to $(Q, t)$. Hence if type 1 is in an equilibrium pool so are all higher types.

Now we show that all types $i \geq 1$ pool with probability one. If $\Pi_{1}^{*}$ is the equilibrium payoff for 1 , it must be that $\Pi_{1}^{*} \geq \Pi_{1}^{s}$. Monotonicity in $t$ implies that for all $Q$ the isoprofit curve yielding profit $\Pi_{1}^{*}$ is below the complete information isoprofit curve for 1. By Lemma 3 the response of the government to $Q^{*}$ must be $t^{*}=Q^{*}+\tau_{0}$ and the equilibrium isoprofit curve for $i \geq 2$ giving payoff $\Pi_{i}^{*}$ must be everywhere below the equilibrium curve for 1 by Lemma 3. Since the isoprofit locus defined by $\Pi_{1}^{s}$ is under $t=\tilde{t}_{1}, \forall Q$, the equilibrium payoff for $i \geq 2$ must be strictly higher than producing any $Q$ in combination with $\tilde{t}_{1}$.

The description of the equilibrium isoprofit curves given by Lemma 3 implies that $\forall Q \neq Q^{*}$ and $i \geq 2$

$$
E_{i}^{0}(Q) \cup E_{i}(Q) \subseteq E_{1}(Q)
$$

Hence in a $D_{1}$ equilibrium the beliefs of the government at $Q \neq Q^{*}$ must place proba-

bility one on 1 and the corresponding duty should be $\tilde{t}_{1}$. As shown above, every type $i$, $i \geq 2$, is strictly better off in equilibrium than producing $Q$ in combination with $\tilde{t}_{1}$; hence, every $i \geq 2$ exports $Q^{*}$ with probability one.

We now consider the government's and type 1's equilibrium strategies. Let $t^{e} \equiv$ $\operatorname{argmax}_{t} w(\mu, t) \geq \tau_{0}$ denote the ex-ante optimal duty. 
First suppose that the prior probability, $\mu$, is such that $\Pi_{1}^{s} \geq \Pi_{1}\left(Q^{e}=t^{e}-\tau_{0}, t^{e}\right)$. We claim that in this case, type 1 can not pool with probability one in any sequential equilibrium. This follows from the fact that if 1 pools with probability one, then the unique best response of the government would be $t^{e}$ to the quantity $Q^{e}=t^{e}-\tau_{0}$. The point $\left(Q^{e}, t^{e}\right)$ is strictly inferior for 1 compared to full separation at $\widetilde{Q}_{1}$. This implies that the only possible solution must involve partial pooling.

As argued above, in any $D_{1}$ pooling equilibrium all disequilibrium beliefs will induce the government to impose $\tilde{t}_{1}$. The strict concavity of 1 's profit function will then guarantee that the only quantity produced with positive probability and met with $\tilde{t}_{1}$ is the unique maximizer, $\widetilde{Q}_{1}$. Moreover, the payoff from such an action must be equal to the payoff at the pooled message if 1 is to randomize. This implies that the pool must occur at the point of intersection of 1's complete information isoprofit curve (10) and the tangency locus. Denote this quantity $Q^{p}$. Since $\Pi_{1}\left(Q, B R\left(Q^{p},\left.\rho \mu\right|_{i \geq 2}+(1-\rho) \mu\right)\right)$ is a continuous strictly increasing function of $\rho$ there exists a unique solution to

$$
\Pi_{1}^{s}=\Pi_{1}\left(Q^{p}, B R\left(Q^{p},\left.\rho \mu\right|_{i \geq 2}+(1-\rho) \mu\right)\right)
$$

such that if 1 puts weight $\rho$ on $Q^{p}$ and $1-\rho$ on $\widetilde{Q}_{1}, t^{p}$ would be the unique best response to $Q^{p}$.

Second, suppose now that the prior probability, $\mu$, is such that $\Pi_{1}^{s}<\Pi_{1}\left(Q^{e}=t^{e}-\right.$ $\left.\tau_{0}, t^{e}\right)$. In this case type 1 would rather pool at $Q^{e}=t^{e}-\tau_{0}$ than separate. The partial pooling equilibrium described in the preceding paragraph is not even sequential in this case since the posterior making $t^{e}$ a sequential best response would require 1 to export $Q^{p}$ with probability larger than one. (Keep in mind that in any $D_{1}$ pooling equilibrium $i \geq 2$ must pool with probability one.) This shows that the only $D_{1}$ equilibrium is in pure strategies at exports $Q^{e}$ and duty level $t^{e}$. The off equilibrium response is $\tilde{t}_{1}, \forall Q \neq Q^{e}$. The domestic firm produces according to (8) in response to $Q^{e}$.

Finally, note that if $t^{e}<\tau_{0}$ then no $\mathrm{AD}$ petition will be filed in equilibrium and the firms simply maximize profits myopically and the tariff remains at $\tau_{0}$.

\section{Proof of Proposition 4}

Proof: Let $Q_{i}^{s}$, as defined in Corollary 2, be the unique candidate for a $D_{1}$ separating equilibrium strategy for $i$. Then $\Pi_{i}^{s}=\Pi\left(Q_{i}^{s}, \tilde{t}_{i}-\tau_{0}\right)$.

To show necessity observe that $\Pi_{T-1}^{s}>\Pi_{T-1}\left(Q=\tilde{t}_{T}-\tau_{0}, \tilde{t}_{T}\right)$ implies $\Pi_{i}^{s}>\Pi_{i}(Q=$ 
$\left.\tilde{t}_{T}-\tau_{0}, \tilde{t}_{T}\right)$ by Lemma 1 . It follows that $Q_{i}^{s}>Q=\tilde{t}_{i}-\tau_{0}$ for all $i$, and $Q_{i}^{s}<Q_{i-1}^{s}$. Hence by Lemma 1 the isoprofit curve for $i$ through $\left(Q_{i}^{s}, \tilde{t}_{i}\right)$ has a slope smaller than the isoprofit curve of type $i-1$ through the same point. In fact the isoprofit curve for type $i$ is below the curve for type $i-1$ for export levels higher than $Q_{i}^{s}$ and above the curve for $i-1$ at quantities smaller than $Q_{i}^{s}$. Hence $D_{1}$ requires that the beliefs of the government be placed on type $i-1$ at off equilibrium exports $Q \in\left(Q_{i}^{s}, Q_{i-1}^{s}\right)$ for all $i$. Above $\widetilde{Q}_{1}$ the government levies a duty of $\tilde{t}_{1}-\tau_{0}$, and below $Q_{T}^{s}$ the response is $\tilde{t}_{T}-\tau_{0}$. These beliefs support the outcome in which every type $i$ exports a distinct quantity $Q_{i}^{s}$ with probability one as the unique outcome of the game. By Lemma 2 no pooling equilibria exist.

We now show that if the condition of the proposition holds there exists a unique $D_{1}$ equilibrium and that in this outcome all but possibly the lowest types export the same quantity with positive probability.

Assume that $\Pi_{T-1}^{s}>\Pi_{T-1}\left(Q=\tilde{t}_{T}-\tau_{0}, \tilde{t}_{T}\right)$ and let type $i$ be the smallest type such that $\Pi_{i}^{s}>\Pi_{i}\left(Q=\tilde{t}_{T}-\tau_{0}, \tilde{t}_{T}\right)$. According to Corollary 1 for each $j \geq i$ there exists a unique point $\left(\hat{Q}_{j}=\hat{t}_{j}-\tau_{0}, \hat{t}_{j}\right)$ such that $\Pi_{j}^{s}=\Pi_{j}\left(\hat{Q}_{j}, \hat{t}_{j}\right)$. Recall that if a type prefers a point along the tangency locus to its separating strategy so does every higher type. Hence if a type pools, every higher type produces the pooled quantity with probability one by Corollary 3. Every type lower than $i$ separates with a pure strategy. We now construct the unique equilibrium by induction on $j$.

1. Suppose that $t\left(\left.\mu\right|_{j \geq i}\right) \leq \hat{t}_{i}$. In this case all $j \geq i$ pool with probability one at $Q=t\left(\left.\mu\right|_{j \geq i}\right)-\tau_{0}$. The unique sequentially rational response to the pooled quantity is $t\left(\left.\mu\right|_{j \geq i}\right)$.

2. If $t\left(\left.\mu\right|_{j \geq i}\right)>\hat{t}_{i}$ we have two possibilities.

(a) Assume that $t\left(\left.\mu\right|_{j \geq i+1}\right)<\hat{t}_{i}$. In this case there exists a unique mixed strategy for type $i$ in which it randomizes between $Q_{i}^{s}$ and $\hat{Q}_{i}$ in a way that makes $\hat{t}_{i}$ a sequential response for the government. (The construction of the mixed strategy for $i$ is the same as the one for type 1 in Proposition 3.) All $j \geq i$ export $\hat{Q}_{i}$ with probability one.

(b) Let $t\left(\left.\mu\right|_{j \geq i+1}\right) \geq \hat{t}_{i}$. If type $i$ pools we know that all $j \geq i$ would pool with probability one. Hence the equilibrium response of the government must be 
bigger than $t\left(\left.\mu\right|_{j \geq i+1}\right)$. This implies that $i$ would separate at $Q_{i}^{s}$.

Suppose now that all types smaller than a type $r>i$ separate. From the preceding analysis it must be that $t\left(\left.\mu\right|_{j \geq r}\right) \geq \hat{t}_{r-1}$.

1. If $t\left(\left.\mu\right|_{j \geq r}\right) \leq \hat{t}_{r}$ then all $j \geq r$ produce $Q=t\left(\left.\mu\right|_{j \geq r}\right)-\tau_{0}$ with probability one.

2. If $t\left(\left.\mu\right|_{j \geq r}\right)>\hat{t}_{r}$ we are facing two scenarios.

(a) Let $t\left(\left.\mu\right|_{j \geq r+1}\right)<\hat{t}_{r}$. In this case $r$ mixes between $Q_{r}^{s}$ and $\hat{Q}_{r}$, all $j \geq r$ export $\hat{Q}_{r}$ with probability one, and the equilibrium duty is $\hat{t}_{r}-\tau_{0}$.

(b) If $t\left(\left.\mu\right|_{j \geq r+1}\right) \geq \hat{t}_{r}$ type $r$ separates at $Q_{r}^{s}$ with probability one.

This completes the induction.

Since by assumption $\hat{t}_{T-1}>\tilde{t}_{T}$ separation is not feasible for $T-1$ by the above construction. Hence in any $D_{1}$ equilibrium at least types $T$ and $T-1$ export the same quantity with positive probability.

It is easy to see that if $i$ is the lowest type in a pool, $D_{1}$ restricts the off equilibrium response of the government to $\tilde{t}_{i}$ in the neighborhood of the pool where the equilibrium isoprofit curve for $i$ is above that of $i-1$. For lower quantity levels the beliefs are concentrated on the type willing to break the equilibrium at the highest duty. By Lemma 1 this is necessarily a type smaller than $i$. For export levels where the equilibrium isoprofit curve of $i$ is below the isoprofit curve for $i-1$ but (necessarily) lower than $Q_{i-1}^{s}$ the beliefs are concentrated on $i-1$. For any $j \leq i-1$ the beliefs of the government are placed on $j-1$ between $Q_{j}^{s}$ and $Q_{j-1}^{s}$. For export levels higher than the equilibrium quantity of type 1 the response is $\tilde{t}_{1}$. This is the unique system of beliefs which satisfy $D_{1}$ and they trivially support the pooling outcome of the game. 